\title{
Evapotranspiration and crop coefficients for a super intensive olive orchard. An application of SIMDualKc and METRIC models using ground and satellite observations
}

\author{
Teresa A. Paço ${ }^{a, *}$, Isabel Pôças ${ }^{a, b}$, Mário Cunha ${ }^{\text {b,c }}$, José C. Silvestre ${ }^{a, d}$, Francisco L. Santos ${ }^{\text {, }}$ \\ Paula Paredes ${ }^{a}$, Luís S. Pereira ${ }^{a}$ \\ a CEER Biosystems Engineering, Instituto Superior de Agronomia, Universidade de Lisboa, Tapada da Ajuda, 1349-017 Lisboa, Portugal \\ ${ }^{\mathrm{b}}$ Centro de Investigação em Ciências Geo-Espaciais (CICGE), Rua do Campo Alegre, 4169-007 Porto, Portugal \\ ${ }^{\mathrm{c}}$ Faculdade de Ciências da Universidade do Porto, Rua do Campo Alegre, 4169-007 Porto, Portugal \\ ${ }^{\mathrm{d}}$ INIAV I.P., Dois Portos, Portugal \\ e Instituto de Ciências Agrárias e Ambientais Mediterrânicas (ICAAM), Universidade de Évora, Largo dos Colegiais, Évora, Portugal
}

\section{A R T I C L E I N F O}

\section{Article history:}

Received 23 December 2013

Received in revised form 17 July 2014

Accepted 27 September 2014

Available online 13 October 2014

This manuscript was handled by

Konstantine P. Georgakakos, Editor-in-Chief,

with the assistance of Venkat Lakshmi

Associate Editor

\section{Keywords:}

Density coefficient

Dual crop coefficients

Eddy covariance

Evapotranspiration partition

Remote sensing

Sap-flow measurements

\section{S U M M A R Y}

The estimation of crop evapotranspiration $\left(\mathrm{ET}_{\mathrm{c}}\right)$ from the reference evapotranspiration ( $\mathrm{ET}_{\mathrm{o}}$ ) and a standard crop coefficient $\left(K_{\mathrm{c}}\right)$ in olive orchards requires that the latter be adjusted to planting density and height. The use of the dual $K_{\mathrm{c}}$ approach may be the best solution because the basal crop coefficient $K_{\mathrm{cb}}$ represents plant transpiration and the evaporation coefficient reproduces the soil coverage conditions and the frequency of wettings. To support related computations for a super intensive olive orchard, the model SIMDualKc was adopted because it uses the dual $K_{\mathrm{c}}$ approach. Alternatively, to consider the physical characteristics of the vegetation, the satellite-based surface energy balance model METRICTM Mapping EvapoTranspiration at high Resolution using Internalized Calibration - was used to estimate $\mathrm{ET}_{\mathrm{c}}$ and to derive crop coefficients. Both approaches were compared in this study. SIMDualKc model was calibrated and validated using sap-flow measurements of the transpiration for 2011 and 2012. In addition, eddy covariance estimation of $\mathrm{ET}_{\mathrm{c}}$ was also used. In the current study, METRICTM was applied to Landsat images from 2011 to 2012. Adaptations for incomplete cover woody crops were required to parameterize METRIC. It was observed that $\mathrm{ET}_{\mathrm{C}}$ obtained from both approaches was similar and that crop coefficients derived from both models showed similar patterns throughout the year. Although the two models use distinct approaches, their results are comparable and they are complementary in spatial and temporal scales.

(c) 2014 Elsevier B.V. All rights reserved.

\section{Introduction}

Olive orchards are a major perennial crop in the Mediterranean agricultural systems; in Southern Europe they account for $49 \%$ of the olive harvested area in the world (FAOSTAT, 2011). In the last decade, traditional orchards (with less than 100 trees ha $^{-1}$ ) are progressively abandoned due to economic reasons (Duarte et al., 2008) and are being replaced by highly productive irrigated hedgerow orchards, with very high trees density (up to 2000 trees ha ${ }^{-1}$ ). In Portugal, this intensification is particularly important in the South of the country, where the Mediterranean climate prevails. The high crop water demand of these dense canopies results in

\footnotetext{
* Corresponding author.

E-mail address: tapaco@isa.ulisboa.pt (T.A. Paço).
}

high irrigation requirements. They are also more demanding in capital and management than the traditional systems but provide higher economic returns (Freixa et al., 2011). In such context it becomes important to improve irrigation management and the adoption of sustainable irrigation practices which help coping with the scarcity of water in the Mediterranean regions. An accurate estimation of crop water requirements, i.e., crop evapotranspiration, $\mathrm{ET}_{\mathrm{c}}$, and its spatio-temporal variability at field level are therefore important when aiming at optimizing irrigation management.

$\mathrm{ET}_{\mathrm{c}}$ of irrigated olive orchards depends on the tree size and density, which influence the ground cover fraction, and on the wetted surface and frequency of wettings by irrigation and rain (Testi et al., 2004; Orgaz et al., 2006; Allen and Pereira, 2009). It is well known that the evaporation from the soil can represent an important fraction of $\mathrm{ET}_{\mathrm{c}}$ from olive orchards since a large fraction of the soil surface in olive is exposed to solar radiation (Bonachela et al., 
1999; Villalobos et al., 2000; Testi et al., 2004, 2006b). On the other hand, olive transpiration is controlled by stomatal conductance, relates with the olive variety and also depends upon crop density, age, LAI, and tree architecture (Villalobos et al., 2000; Orgaz et al., 2006; Testi et al., 2006a; Allen and Pereira, 2009). Moreover, it is important to accurately estimate olive evapotranspiration adjusted to local environmental and cultivation conditions throughout the crop season because, despite olives are well adapted to dry Mediterranean conditions, yields are highly influenced by water stress (Moriana et al., 2003; Lavee et al., 2007; Iniesta et al., 2009; Palese et al., 2010). In addition, water amounts can be adjusted to limit excessive growth in non-bearing years (Aïachi Mezghani et al., 2012). For the specific case of hedgerow olive orchards, vegetative growth also needs to be controlled in order to keep an adequate tree size for mechanical harvesting and an appropriate exposure of canopy walls to solar radiation (Cuevas et al., 2013).

Olive $\mathrm{ET}_{\mathrm{c}}$ is often estimated with the widely adopted $K_{\mathrm{c}}-\mathrm{ET}_{\mathrm{o}}$ approach where the grass reference evapotranspiration, $\mathrm{ET}_{0}$, is multiplied by a crop coefficient adjusted to environmental conditions, $K_{c}$ (Allen et al., 1998). The $\mathrm{ET}_{\mathrm{o}}$ represents the climatic demand and the $K_{\mathrm{c}}$ expresses the differences between the olive crop and the reference grass crop in terms of crop height and aerodynamic characteristics, crop-soil surface resistance, and albedo of the crop-soil surface. Adopting single crop coefficients both crop transpiration and soil evaporation are integrated into a time averaged $K_{\mathrm{c}}$; differently, with the dual approach, $K_{\mathrm{c}}$ consists of a basal crop coefficient $\left(K_{\mathrm{cb}}\right)$, representing primarily the plant transpiration component of $\mathrm{ET}_{\mathrm{c}}$, and an evaporation coefficient $\left(K_{\mathrm{e}}\right)$, that characterizes soil evaporation as described in Section 2.3 where the model is characterized.

The dual $K_{\mathrm{c}}$ approach is particularly interesting because it allows estimating transpiration, that is a main driving factor for crop development and yielding, which mainly depend on transpiration and not on ET (Lavee et al., 2007). $K_{\mathrm{c}}$ and $K_{\mathrm{cb}}$ are standardized for no stress and high crop yielding; otherwise they need to be adjusted to take into account the effect of water stress by considering a multiplicative stress coefficient $\left(K_{\mathrm{s}}\right)$, thus originating $K_{\mathrm{c}}$ adj or $K_{\mathrm{cb}}$ adj. The dual $K_{\mathrm{c}}$ approach is particularly suitable for crops having incomplete ground cover, where soil evaporation is especially related with the fraction of soil surface wetted by irrigation and exposed to radiation (Allen et al., 1998, 2005a), as for olive orchards. This approach involves some complexity but adapts well to partial cover woody crops (Er-Raki et al., 2010; Paço et al., 2012), including when an active ground cover exists (Allen and Pereira, 2009; Fandiño et al., 2012).

In alternative to adopting the dual $K_{\mathrm{c}}$ approach for partitioning ET into soil evaporation and crop transpiration, that partition in woody crops is often performed through specific observations of the soil evaporation with microlysimeters and of the plant transpiration with sap-flow measurements (Fernández et al., 2001; Paço et al., 2012; Cammalleri et al., 2013; Cuevas et al., 2013). This approach is appropriate to calibrate/validate a dual $K_{\mathrm{c}}$ modeling approach.

Standard crop coefficients $K_{\mathrm{c}}$ and $K_{\mathrm{cb}}$ are defined and tabulated for a wide range of agricultural crops including olives (Allen et al., 1998) and were updated and extended for woody crops having various heights and densities (Allen and Pereira, 2009), and can be transferable to different regions and climates. Various studies have been developed with derivation of crop coefficients for olive orchards but with results largely varying with management (e.g., Villalobos et al., 2000; Ramos and Santos, 2009; Er-Raki et al., 2010; Cammalleri et al., 2013). Thus, the adjustment of crop coefficients is required taking into consideration planting density and vegetation height. To overcome the complexity of related computations throughout the crop season, a model may be used. Several approaches have been proposed to adopt the single $K_{\mathrm{c}}$ approach (e.g., Villalobos et al., 2000, 2013; Testi et al., 2006b; Abazi et al., 2013). Orgaz et al. (2006) presented an empirical approach to compute crop coefficients. Bonachela et al. (1999) developed a soil evaporation model modified from that of Ritchie (1972). However, models using the dual $K_{\mathrm{c}}$ approach were not used for olive orchards, thus modeling super intensive, i.e., super high density olive orchards with the dual crop coefficient approach is innovative. Hence, in this study, the SIMDualKc soil water balance model (Rosa et al., 2012a) is adopted. It applies the dual crop coefficient approach, thus it partitions daily ET into soil evaporation and crop transpiration. By adopting a density coefficient, it has been shown appropriate for the computation of $\mathrm{ET}_{\mathrm{c} \text { adj }}$ for crops that do not completely cover the ground, including when active ground cover exists (Paço et al., 2012; Fandiño et al., 2012).

An alternative approach to assess $\mathrm{ET}_{\mathrm{c}}$ and to obtain crop coefficients is to use remote sensing data and tools. This approach has a strong advantage in spatial accuracy because allows obtaining information for each pixel of a satellite image. Therefore, it is possible to characterize individual fields and evaluate their specificities regarding plant density and other crop conditions. Satellite-based surface energy balance models have been successfully applied to estimate and map evapotranspiration (e.g., Bastiaanssen, 2000; Minacapilli et al., 2009; Anderson et al., 2012; Cammalleri et al., 2012; Tian et al., 2013) and derive crop coefficients. METRIC ${ }^{\mathrm{TM}}$ - Mapping EvapoTranspiration at high Resolution using Internalized Calibration - (Allen et al., 2007b) is one of such models. METRIC has been used over an extensive range of vegetation types and applications, mostly focusing annual crops (e.g., Allen et al., 2007a; Tasumi and Allen, 2007; Anderson et al., 2012; Pôças et al., 2013), but also for olive orchards (Santos et al., 2012). The METRICTM model estimates the ET flux for each pixel of a satellite imagery (containing both short wave and thermal information) as a "residual" of the surface energy balance at the time of satellite overpass, i.e., by subtracting the soil heat flux and sensible heat flux from the net radiation at the surface. The METRIC model provides for obtaining the fraction ETrF of the alfalfa reference $\mathrm{ET}_{\mathrm{r}}$ adopted in the model. ETrF is a crop coefficient relative to $\mathrm{ET}_{\mathrm{r}}\left(K_{\mathrm{cr}}\right)$ since alfalfa is the reference crop adopted in METRIC (Allen et al., 2005b, 2011b). It is defined as the ratio of the crop $\mathrm{ET}\left(\mathrm{ET}_{\mathrm{c}}\right)$ at the time of the satellite overpass for each pixel to the alfalfa reference ET computed from weather data $\left(\mathrm{ET}_{\mathrm{r}}\right)$. By computing a crop coefficient based on the estimated $\mathrm{ET}_{\mathrm{c}}$, it allows to directly integrate factors related with orchard architecture, agricultural practices and environmental conditions (such as irrigation, water stress occurrence, salinity or diseases). If appropriate knowledge on $\mathrm{ET}_{\mathrm{c}}$ and crop coefficients is available, it becomes easier to develop farm irrigation practices that minimize non-beneficial water consumption and use, and lead to increased water productivity and farm incomes. This METRIC application to partial cover woody crops, such as olive orchards is innovative and requires specific adjustments.

The present study aims at providing information on evapotranspiration and crop coefficients for a super high density olive orchard by considering the physical characteristics of the vegetation, i.e., the plant density and height. Specific objectives include the calibration of SIMDualKc model with transpiration data derived from sap-flow measurements, which is different from the commonly performed calibration, and its test using limited ET data obtained with the eddy covariance technique. The study also aims at the computation of crop coefficients from ground and satellite observations, respectively using the SIMDualKc model and the METRIC algorithm, and analyzing and comparing ET and $K_{\mathrm{c}}$ results obtained through both modeling approaches. The resulting information shall be later used to support improved irrigation management programs aimed at coping with water scarcity and improving the beneficial water uses, particularly exploring the complementarity 
between METRIC and SIMDualKc given the temporal and spatial specificities of both models.

\section{Material and methods}

\subsection{Study area}

The study area (38 $28^{\prime} 46^{\prime \prime} \mathrm{N}, 7^{\circ} 43^{\prime} 40^{\prime \prime} \mathrm{W}, 143 \mathrm{~m}$ a.s.l.) is located in a commercial super intensive olive orchard near Viana do Alentejo, in Alentejo, Southern Portugal (Fig. 1). Climate is dry sub-humid of the Mediterranean type, with an average annual rainfall between 600 and $800 \mathrm{~mm}$, mainly concentrated in the autumn and winter periods, and an average monthly temperature ranging from $9.6{ }^{\circ} \mathrm{C}$ in January to $24.1^{\circ} \mathrm{C}$ in August. Reference evapotranspiration ( $\mathrm{ET}_{\mathrm{o}}$ ) was computed according to Allen et al. (1998) with meteorological data collected at a nearby automated weather station (Viana do Alentejo weather station located east of the field plot $\left(38^{\circ} 21^{\prime} 42^{\prime \prime} \mathrm{N}, 08^{\circ} 07^{\prime} 29^{\prime \prime} \mathrm{W}\right.$, and elevation $138 \mathrm{~m}$ ). The weather station installed in the field produced incomplete data due to malfunctioning of the equipment and available data were compared with those of Viana do Alentejo showing to be similar. Parallel studies on spatial and temporal variability of precipitation (Martins et al., 2012) and temperature (Raziei et al., 2013) confirmed the adequateness for using a full data set from Viana do Alentejo. Dominating winds in the region blow from the NW quadrant. Mean weather variables for both study years are shown in Table 1.

The olive orchard is explored by a commercial farm ("Olivais do Sul") and presents very high density tree planting of the cultivar Arbequina $\left(1.35 \mathrm{~m} \times 3.75 \mathrm{~m}, 1975\right.$ trees $\mathrm{h}^{-1}$ ), with a total area of approximately 78 ha with undulated terrain. The fraction of ground covered by the vegetation was $f_{\mathrm{c}} \approx 0.35$ and tree height was around $3.5 \mathrm{~m}$. The olive orchard was planted in 2006 and is managed in a hedgerow system with tree branches interlinked. In 2012 the orchard was affected by a heavy frost that occurred from 20th to 25th February and caused a strong leaf fall, which was consequently followed by a heavy pruning. This affected the fraction of ground cover and was accounted for in the modeling process.
The olive orchard was irrigated almost every day, by the evening, during spring and summer, with a drip system having emitters with $0.75 \mathrm{~m}$ spacing along the row and discharging $2.3 \mathrm{~L} \mathrm{~h}^{-1}$. The average daily irrigation amounts were close to $3 \mathrm{~mm} \mathrm{~d}^{-1}$ during the irrigation season; the wetted fraction $\left(f_{\mathrm{w}}\right)$ was about 0.23 . Irrigation data (dates and water depths) were provided by the farm managers of "Olivais do Sul" and were locally measured with a tipping-bucket raingauge (ARG100, Environmental Measurements Ltd., Sunderland, UK).

The soil in the field is a sandy loam, with average clay, silt and sand contents averaging $17 \%, 6 \%$ and $77 \%$, respectively. The soil water content, determined from the average water retention curve, was $0.24\left(\mathrm{~cm}^{3} \mathrm{~cm}^{-3}\right)$ at field capacity $\left(\theta_{\mathrm{FC}}\right)$ and $0.12\left(\mathrm{~cm}^{3} \mathrm{~cm}^{-3}\right)$ at the permanent wilting point $\left(\theta_{\mathrm{WP}}\right)$. The average total available soil water in the root zone (TAW) assumed for modeling was $144 \mathrm{~mm}$ for a soil depth of $1.2 \mathrm{~m}$.

\subsection{Field data}

Data obtained from ground-based measurements were used to validate information obtained through the simulation models. Plant transpiration was assessed using sap-flow measurements by the Granier method (Granier, 1985) during the period 137/ 2011 to 366/2012 DOY (day of year). A set of six $1 \mathrm{~cm}$ length sensors (UP GmbH, Germany) was distributed by seriated trees, according to trunk diameter class frequency, established in a larger sample of the plot. Thirty-minute data were stored in a datalogger (Model CR1000, Campbell Scientific, Inc., Logan, UT, USA). Natural temperature gradients in the tree trunk were corrected using data from non-heated sap-flow sensors during long periods.

Soil evaporation was measured with a set of six microlysimeters, built from PVC pipes as described by Daamen et al. (1993), and located in three areas representing different soil surface wetness/exposure: (i) between rows and in non-irrigated areas, (ii) in the crop row at a midpoint between emitters, and (iii) in the crop row near the emitters.

Evapotranspiration measurements were performed by the eddy covariance (EC) micrometeorological technique using a threedimensional sonic anemometer and a krypton hygrometer (for

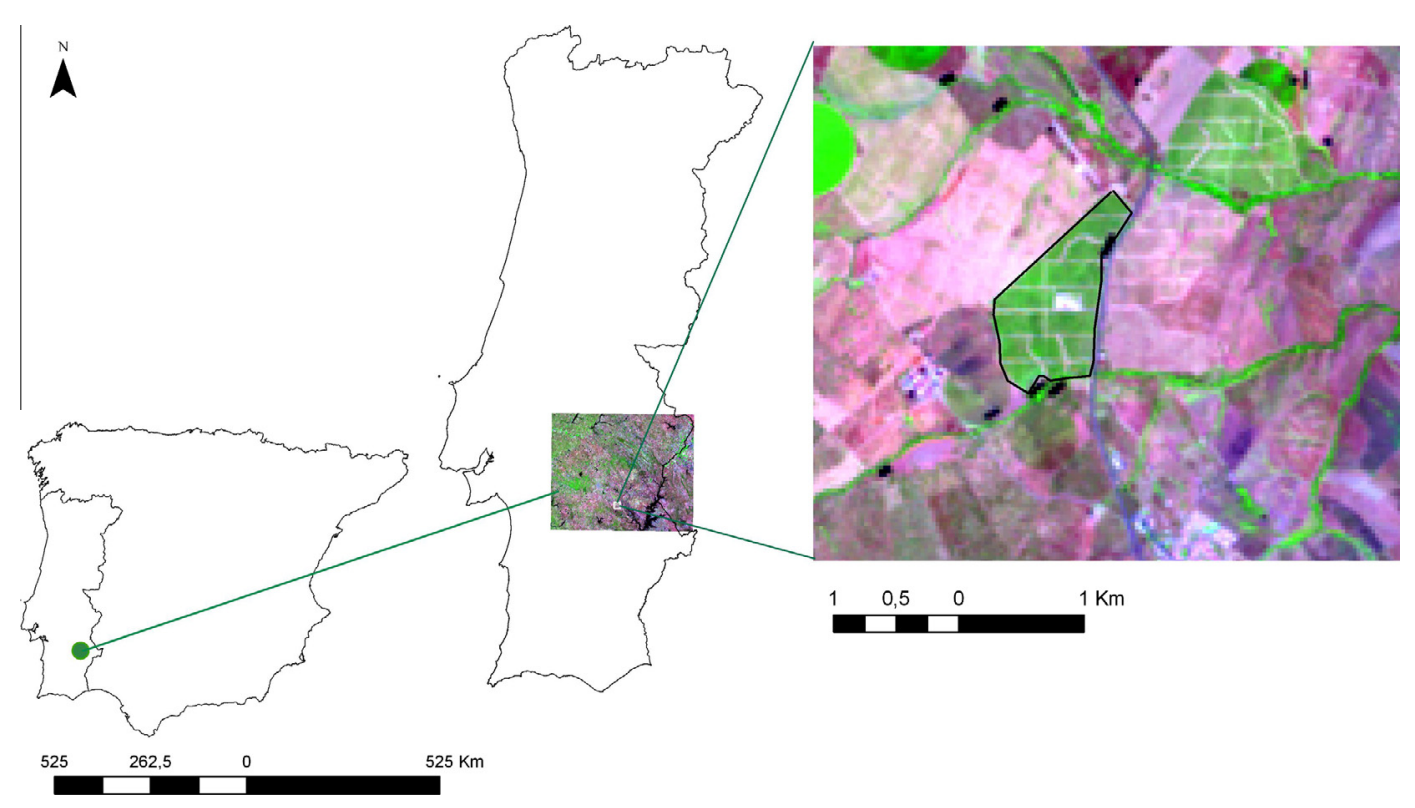

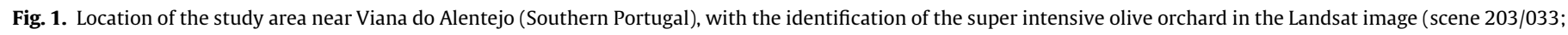
RGB combination 5:4:3). 
Table 1

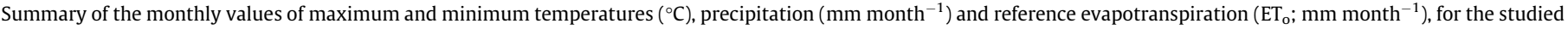
years.

\begin{tabular}{|c|c|c|c|c|c|c|c|c|}
\hline \multirow[t]{2}{*}{ Month } & \multicolumn{2}{|c|}{ Mean maximum temperature $\left({ }^{\circ} \mathrm{C}\right)$} & \multicolumn{2}{|c|}{ Mean minimum temperature $\left({ }^{\circ} \mathrm{C}\right)$} & \multicolumn{2}{|c|}{ Precipitation $\left(\mathrm{mm}\right.$ month $\left.^{-1}\right)$} & \multicolumn{2}{|c|}{$\mathrm{ET}_{\mathrm{o}}\left(\mathrm{mm} \mathrm{month}^{-1}\right)$} \\
\hline & 2011 & 2012 & 2011 & 2012 & 2011 & 2012 & 2011 & 2012 \\
\hline January & 14.1 & 15.8 & 5.4 & 2.8 & 76.1 & 15.0 & 29.0 & 32.8 \\
\hline February & 17.1 & 16.0 & 4.8 & 0.0 & 62.5 & 0.6 & 44.2 & 58.8 \\
\hline March & 17.9 & 21.3 & 6.5 & 5.7 & 39.3 & 25.1 & 67.0 & 92.3 \\
\hline April & 24.6 & 18.0 & 10.7 & 6.9 & 94.6 & 39.1 & 109.3 & 76.7 \\
\hline May & 27.6 & 26.5 & 13.1 & 11.2 & 101.7 & 16.9 & 134.9 & 135.8 \\
\hline June & 30.1 & 29.9 & 12.6 & 13.5 & 46.0 & 0.3 & 166.3 & 169.6 \\
\hline July & 31.8 & 32.8 & 13.8 & 13.9 & 1.0 & 0.6 & 198.2 & 205.6 \\
\hline August & 31.7 & 32.7 & 14.9 & 15.0 & 7.8 & 3.9 & 167.1 & 182.7 \\
\hline September & 30.7 & 30.3 & 13.7 & 14.9 & 49.7 & 41.5 & 127.2 & 134.4 \\
\hline October & 28.1 & 23.3 & 122 & 11.4 & 44.8 & 95.1 & 104.1 & 72.4 \\
\hline November & 17.7 & 16.6 & 8.5 & 7.9 & 141.1 & 227.6 & 36.8 & 31.7 \\
\hline December & 15.4 & 15.9 & 4.3 & 6.5 & 12.5 & 61.6 & 25.7 & 26.0 \\
\hline
\end{tabular}

wind velocity and water vapour fluctuations measurement, respectively, Models CSAT3 and KH20, Campbell Scientific, Inc., Logan, UT, USA) connected to a datalogger (Model CR1000, Campbell Scientific, Inc., Logan, UT, USA). Observations were performed from the end of July until the end of August in 2011 and from the middle of June until the end of August in 2012 (summer periods without rainfall since the krypton hygrometer used for water vapor fluctuations measurement would suffer damage should it get wet). The sensors were placed on a metallic tower at a measurement height of $4.8 \mathrm{~m}$. Eddy covariance raw data $(H$ - sensible heat flux density and $\lambda E$ - latent heat flux density) were collected at a $10 \mathrm{~Hz}$ frequency and further analyzed with the Software package TK3 (University of Bayreuth, Germany) for correction and calculation of EC 30-min data. Data corrections were performed following Foken et al. (2011) and raw data were submitted to a coordinate rotation using the Double Rotation method (Kaimal and Finnigan, 1994) given the non-flat terrain conditions. The spatial representativeness of the measurements was examined through a footprint analysis (Schuepp et al., 1990). Soil heat flux $(G)$ was measured using eight soil heat flux plates (calibrated Peltier modules sealed $20 \mathrm{~V}$, $4.4 \mathrm{~A}, 40 \times 40 \times 3.9 \mathrm{~mm}$, RS Components, Madrid, Spain) placed in the tree row and between tree rows, at a depth of $2 \mathrm{~cm}$. Net radiation $\left(R_{\mathrm{n}}\right)$ was measured with a net radiometer (Model NR-LITE, Campbell Scientific, Inc., Logan, Utah, USA). Surface energy balance evaluation provided an energy balance equation error closure below $10 \%$, determined for daily values by linear regression forced to origin $\left(\lambda E+H=0.91\left(R_{\mathrm{n}}-G\right), R^{2}=0.87\right)$. Data from days with wind from the NE direction were discarded given the vicinity of a building, approximately at $200 \mathrm{~m}$ in that direction. All other directions were considered valid, providing that over $88 \%$ to $96 \%$ of the fluxes were coming from the region of interest, as determined by the footprint analysis. For specific modeling purposes, data was further serialized by quality labels, according to fetch conditions.

In previous studies (e.g., Silva et al., 2008) Granier sap-flow method was found to underestimate transpiration, especially for high flux densities; therefore the original calibration of the method was verified. The procedure to obtain calibrated sap-flow $\left(T_{\mathrm{sf}}\right)$ is described by Ferreira et al. (2004), Silva et al. (2008) and Paço et al. (2012). In this procedure, the EC technique is used for a short period of time and related to sap-flow data. This strategy allowed obtaining long-term series of $T_{\mathrm{sf}}$ with this simple automated technique, without the need to perform micrometeorological observations during the whole study period. This procedure consisted in regressing sap flow against transpiration obtained from EC evapotranspiration minus soil evaporation, hence relating transpiration measured by two different techniques. For this procedure, soil evaporation was obtained with the Ritchie model (Ritchie, 1972), as further explained later in the text. To calibrate and validate the SIMDualKc model (Rosa et al., 2012a) daily transpiration data were used, thus comparing transpiration simulated by SIMDualKc $\left(T_{\text {sim }}\right)$ with $T_{\mathrm{sf}}(n=209$ in 2011 for calibration and $n=366$ in 2012 for validation).

The number of days when EC data was appropriate $(n=13$ in 2011 and $n=28$ in 2012) was insufficient to calibrate and validate the SIMDualKc model. EC data for 2012 were used to test the SIMDualKc model through a direct comparison between $\mathrm{ET}_{\mathrm{ec}}$ and simulated ET $\left(\mathrm{ET}_{\text {sim }}\right)$.

Soil evaporation $\left(E_{s}\right)$ is simulated with the two stages Ritchie's model (Ritchie, 1972) that is adopted in the FAO56 dual $K_{\mathrm{c}}$ methodology (Allen et al., 1998, 2005a). This evaporation model is also used in SIMDualKc to simulate the soil evaporation component of ET (Rosa et al., 2012a) and has previously been validated for various crops (Paço et al., 2012; Zhao et al., 2013; Wei et al., 2014). There was only a limited number of microlysimeter observations (several times along the day for 8 days), thus testing the Ritchie's model in this study could only be partially performed. Good results obtained in the referred studies, particularly for the peach orchard (Paço et al., 2012), and by Bonachela et al. (1999) for olive orchards, allow to assume the goodness of the model in simulating evaporation.

As previously referred, $T_{\mathrm{sf}}$ was used to calibrate and validate the SIMDualKc model. However, since our aim was to obtain crop coefficients and, mainly, to compare ET from METRIC with ET from ground observations, the ET simulated by SIMDualKc $\left(\mathrm{ET}_{\text {sim }}\right)$ was compared with ground based ET data $\left(\mathrm{ET}_{\mathrm{obs}}\right)$. Assuming, as referred above, that $E_{\mathrm{s} \text { sim }}$ using the Ritchie's model represented well the actual $E_{\mathrm{s}}$, then $\mathrm{ET}_{\mathrm{obs}}$ was computed as:

$\mathrm{ET}_{\mathrm{obs}}=T_{\mathrm{sf}}+E_{\mathrm{s} \text { sim }}$

Since the model was already calibrated and validated using transpiration data, the comparison between $\mathrm{ET}_{\text {sim }}$ and $\mathrm{ET}_{\mathrm{obs}}$ provides for model testing to support the derivation of crop coefficients, which is analyzed in the Section 3.4.

\subsection{SIMDualKc model}

As previously mentioned, the SIMDualKc model (Rosa et al., 2012a) uses the dual crop coefficient approach to simulate crop evapotranspiration (Allen et al., 1998, 2005a; Allen and Pereira, 2009) by performing a daily soil water balance at the field scale. In previous studies the model has been calibrated and validated for several crops and field conditions, including woody crops (Fandiño et al., 2012; Paço et al., 2012; Zhao et al., 2013; Wei et al., 2014). 
The model simulates crop evapotranspiration $\left(\mathrm{ET}_{\mathrm{c}}\right)$ using reference evapotranspiration $\left(\mathrm{ET}_{\mathrm{o}}, \mathrm{mm}\right)$ and the basal and soil evaporation coefficients ( $K_{\mathrm{cb}}$ and $K_{\mathrm{e}}$, dimensionless) that relate to respectively crop transpiration $\left(T_{\mathrm{c}}\right)$ and soil evaporation $\left(E_{\mathrm{s}}\right)$ :

$\mathrm{ET}_{\mathrm{c}}=\left(K_{\mathrm{cb}}+K_{\mathrm{e}}\right) \mathrm{ET}_{\mathrm{o}}=K_{\mathrm{cb}} \mathrm{ET}_{\mathrm{o}}+K_{\mathrm{e}} \cdot \mathrm{ET}_{\mathrm{o}}=T_{\mathrm{c}}+E_{\mathrm{s}}$

$\mathrm{ET}_{\mathrm{C}}$ is crop evapotranspiration for no stress conditions. When stress occurs, particularly crop water stress, ET is adjusted by the model as a function of the available soil water in the root zone considering a stress coefficient $\left(K_{\mathrm{s}}\right)$, thus providing $\mathrm{ET}_{\mathrm{c}}$ adj $(\mathrm{mm})$, which is the actual evapotranspiration. If the soil water content $\theta$ remains above $\theta_{\mathrm{p}}$, that is the $\theta$ value corresponding to the depletion fraction for no stress $p$, then $\mathrm{ET}_{\mathrm{c} \text { adj }}=\mathrm{ET}_{\mathrm{c}}$; otherwise $\mathrm{ET}_{\mathrm{c} \text { adj }}<\mathrm{ET}_{\mathrm{c}}$, decreasing with the available soil water:

$\mathrm{ET}_{\mathrm{c} \text { adj }}=\left(K_{\mathrm{s}} K_{\mathrm{cb}}+K_{\mathrm{e}}\right) \mathrm{ET}_{\mathrm{o}}$

where $K_{\mathrm{s}}[0-1]$ is the water stress coefficient, which is computed from the soil water balance as defined by Allen et al. (1998) and Rosa et al. (2012a).

A density coefficient $\left(K_{\mathrm{d}}\right)$ can be used in the computation of $K_{\mathrm{c}}$ or $K_{\mathrm{cb}}$ to take into account plant density and height (Allen and Pereira, 2009). When the inter-row is bare soil, then $K_{\mathrm{cb}}$ is:

$K_{\mathrm{cb}}=K_{\mathrm{c} \min }+K_{\mathrm{d}}\left(K_{\mathrm{cb} \text { full }}-K_{\mathrm{c} \min }\right)$

where $K_{\mathrm{cb}}$ full is the estimated basal $K_{\mathrm{cb}}$ during the peak plant growth for conditions having nearly full ground cover, and $K_{\mathrm{c}} \min$ is the minimum $K_{\mathrm{c}}$ for bare soil ( $\approx 0.15$ for typical agricultural conditions, Allen and Pereira, 2009; Fandiño et al., 2012). $K_{\mathrm{cb}}$ full is estimated primarily as a function of crop height and can be adjusted for tree crops when multiplied by a reduction factor $\left(F_{\mathrm{r}}\right)$ estimated from the mean leaf stomatal resistance. The density coefficient can be estimated from the effective fraction of ground cover as described by Allen and Pereira (2009):

$K_{\mathrm{d}}=\min \left(1, M_{\mathrm{L}} f_{\mathrm{c} \text { eff }}, f_{\mathrm{c} \text { eff }}^{(1 /(1+\mathrm{h}))}\right)$

where $f_{\mathrm{c} \text { eff }}$ is the effective fraction of ground covered or shaded by vegetation near solar noon, $M_{\mathrm{L}}$ is a multiplier on $f_{\mathrm{c}}$ eff describing the effect of canopy density on shading and on maximum relative ET per fraction of ground shaded (to simulate the physical limits imposed on water flux through the plant root, stem and leaf systems), and $h(\mathrm{~m})$ is the mean height of the vegetation.

As previously referred, measured sap-flow data $\left(T_{\text {sf }}\right)$ from 2011 were used to calibrate the SIMDualKc model and validation was performed with $2012 T_{\text {sf }}$ data. The following data sets were further used for model testing: (i) ET obtained with the eddy covariance technique $\left(\mathrm{ET}_{\mathrm{ec}}\right.$ ); (ii) ET obtained from $T_{\mathrm{sf}}+E_{\mathrm{s}}$ sim, i.e. with soil evaporation $E_{\mathrm{s}}$ sim simulated with the Ritchie's model (Ritchie, 1972), which is part of SIMDualKc as previously referred. Model calibration consisted in searching the parameters values that better describe the crop and its environmental conditions, mainly the basal crop coefficients $K_{\mathrm{cb}}$ and the depletion fraction for no water stress $(p)$ relative to the initial-, mid- and end-season crop stages, the $M_{\mathrm{L}}$ factor, the soil evaporation parameters TEW, REW and $Z_{\mathrm{e}}$, the runoff curve number $\mathrm{CN}$, and the deep percolation $a_{\mathrm{D}}$ and $b_{\mathrm{D}}$ parameters, which are defined by Liu et al. (2006).

The calibration and validation methodologies were adapted from those described by Rosa et al. (2012b). Calibration was performed by progressively changing crop, evaporation, runoff, and percolation parameters to minimize the differences between observed and simulated transpiration $\left(T_{\mathrm{sf}}\right.$ and $\left.T_{\mathrm{sim}}\right)$. In addition, the model was tested comparing $\mathrm{ET}_{\text {sim }}$ with $\mathrm{ET}_{\mathrm{ec}}$ and $\mathrm{ET}_{\text {obs. }}$ The density coefficient $\left(K_{\mathrm{d}}\right.$, Eq. $\left.(5)\right)$ was computed for the actual fraction of ground cover $\left(f_{\mathrm{c} \text { eff }}\right)$ and accounting for its reduction caused by frost in 2012 . The $K_{\mathrm{cb}}$ values were computed from $K_{\mathrm{d}}$ (Eq. (4)) with progressively changing the $M_{\mathrm{L}}$ values in Eq. (5); the initial
Table 2

Standard and calibrated parameters used in SIMDualKc model ( $p$ - depletion fraction, $K_{\mathrm{cb} \text { ini }}$ - basal crop coefficient for the initial crop development stage, $K_{\mathrm{cb}}$ mid - basal crop coefficient for the mid stage, $K_{\mathrm{cb}}$ end - basal crop coefficient for the end-season stage, $M_{\mathrm{L}}$ parameter, TEW - total evaporable water, REW - readily evaporable water, $Z_{\mathrm{e}}$ - thickness of the evaporation layer, $\mathrm{CN}$ - curve number, $a_{\mathrm{D}}$ and $b_{\mathrm{D}}$ - deep percolation parameters).

\begin{tabular}{lrr}
\hline & Standard & Calibrated \\
\hline$p$ & 0.50 & 0.40 \\
$K_{\mathrm{cb} \text { ini }}$ & 0.50 & 0.50 \\
$K_{\mathrm{cb} \text { mid }}$ & 0.55 & 0.55 \\
$K_{\mathrm{cb} \text { end }}$ & 0.50 & 0.50 \\
$M_{\mathrm{L}}$ & 2.00 & 1.70 \\
TEW & 18.00 & 18.00 \\
REW & 9.00 & 9.00 \\
$Z_{\mathrm{e}}$ & 0.10 & 0.10 \\
$\mathrm{CN}$ & 72.00 & 72.00 \\
$a_{\mathrm{D}}$ & 246.00 & 246.00 \\
$b_{\mathrm{D}}$ & 0.02 & 0.02 \\
\hline
\end{tabular}

value of $M_{\mathrm{L}}$ was 2.0 (Table 2). Changes in $K_{\mathrm{cb}}$ were made together with those of the fraction $p$ of soil water depletion for no stress, whose initial value was 0.5 . Standard $K_{\mathrm{cb}}$ values used to initialize the model were $K_{\mathrm{cb} \text { ini }}=0.5, K_{\mathrm{cb} \text { mid }}=0.55$ and $K_{\mathrm{cb} \text { end }}=0.5$ according to information proposed by Allen and Pereira (2009) for the estimation of crop coefficients as a function of the fraction of ground cover and crop height.

The evaporation parameters used for calibrating the soil evaporation component of the model, i.e., the Ritchie's model, were: (a) the total evaporable water, TEW $(\mathrm{mm})$, representing the maximum depth of water that can be evaporated from the surface soil layer when it has been initially fully wetted; (b) the readily evaporable water, REW (mm), defined as the cumulative depth of evaporation at the end of stage 1 of the evaporation process, when available energy at the upper soil layer but not the hydraulic conditions is limiting the process; and (c) the thickness of the evaporation layer $Z_{\mathrm{e}}(\mathrm{m})$. The initial values were computed according to Allen et al. (1998); the values retained were $Z_{\mathrm{e}}=0.1 \mathrm{~m}, \mathrm{TEW}=18 \mathrm{~mm}$, and REW $=9 \mathrm{~mm}$ (Table 2).

Precipitation-runoff simulation was performed considering the curve number approach $(\mathrm{CN})$ following the approach proposed by Allen et al. (2007c). A value of $\mathrm{CN}=72$ was selected corresponding to a medium textured soil cropped with fruit trees. The deep percolation parameters were those proposed by Liu et al. (2006) for sandy-loam soils $\left(a_{\mathrm{D}}=246 \mathrm{~mm}, b_{\mathrm{D}}=-0.02\right)$ (Table 2$)$. An active ground cover was present in the first year of the study, covering $10 \%$ of the ground, until the beginning of August. Following the heavy defoliation of trees in February 2012 as a result of frost, a mulch formed by leaves covered the soil; this effect was accounted for in the modeling process (Rosa et al., 2012a) considering a fraction of ground cover corresponding to mulch equal to 0.3 from the end of February until the beginning of August.

Calibration was performed at various steps; first, the $K_{\mathrm{cb}}$ and $p$ values were progressively modified to minimize the differences $T_{\text {sim }}-T_{\text {sf. }}$ After small changes in their values, the initial values of TEW, REW and $Z_{\mathrm{e}}$ were verified to be appropriate for model fitting and, consequently, for estimation of soil evaporation. The values of runoff $\mathrm{CN}$ and percolation parameters $a_{\mathrm{D}}$ and $b_{\mathrm{D}}$ were also kept after unsuccessful attempts to improve fitting (Table 2). These calibration procedures have shown that the most important calibration parameters are $K_{\mathrm{cb}}$ and $p$.

The goodness of fit was assessed with various indicators including a linear regression forced through the origin between $T_{\text {sim }}$ and $T_{\mathrm{sf}}$. The corresponding regression and determination coefficients were used as indicators. Indicators of residual estimation errors were also computed: the root mean square error (RMSE) and the average absolute error (AAE). In addition, two statistical indicators of the quality of modeling were used: the Nash and Sutcliffe (1970) 
modeling efficiency (EF, dimensionless), that is a normalized statistic that determines the relative magnitude of the residuals variance compared to the measured data variance (Moriasi et al., 2007); and the Willmott (1981) index of agreement ( $d_{\mathrm{IA}}$, dimensionless) that represents the ratio between the mean square error and the "potential error" (Moriasi et al., 2007). All referred indicators have been used in former studies with SIMDualKc (e.g., Rosa et al., 2012b; Zhao et al., 2013) where they are described.

In addition, when comparing SIMDualKc and METRIC results the

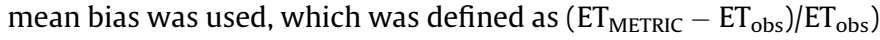
and $\left.\left(\mathrm{ET}_{\mathrm{METRIC}}-\mathrm{ET}_{\text {sim }}\right) / \mathrm{ET}_{\text {sim }}\right)$, where $\mathrm{ET}_{\text {METRIC }}$ is the average $\mathrm{ET}$ estimated with METRIC for the full set of pixels in the study.

\subsection{METRIC algorithm}

The METRIC algorithm was applied to sixteen Landsat5 TM and Landsat7 ETM+ satellite images (path203/row033) with L1T processing level (i.e., with geometric and terrain correction): ten images of the year 2011 - January 31st, March 20th, April 5th, May 23rd, June 24th, July 26th, August 27th, September 12th, October 6th, and October 30th; and six images of the year 2012 - February 11 th, April 15th, July 20th, August 21 st, September 6th, and October 8th.

The METRIC algorithm is based upon the energy balance at the land surface. The latent heat flux $(\lambda E)$ is calculated from the energy balance as:

$\lambda E=R_{\mathrm{n}}-G-H$

where $G$ is the soil heat flux, $H$ is the sensible heat flux, and $R_{\mathrm{n}}$ is the net radiation, all units in $\mathrm{W} \mathrm{m}^{-2}$. The latent heat flux is computed for each pixel at the instant of satellite overpass and is readily converted to instantaneous ET (Allen et al., 2007b):

$\mathrm{ET}_{\text {inst }}=3600 \lambda E / \lambda$

where $\mathrm{ET}_{\text {inst }}$ is the instantaneous $\mathrm{ET}\left(\mathrm{mm} \mathrm{h}^{-1}\right), 3600$ is the time conversion from seconds to hours, $\lambda E$ is the latent heat flux $\left(\mathrm{W} \mathrm{m}^{-2}\right)$, and $\lambda$ is the latent heat of vaporization $\left(\mathrm{J} \mathrm{kg}^{-1}\right)$.

A fraction ETrF is computed for the time of the satellite overpass, $\mathrm{ETrF}_{\text {inst. }}$. This fraction corresponds to the ratio of the instantaneous ET derived for each pixel to the alfalfa reference ET $\left(\mathrm{ET}_{\mathrm{r}}\right)$, thus $\mathrm{ETrF}_{\text {inst }}=\mathrm{ET}_{\text {inst }} / \mathrm{ET}_{\mathrm{r}}$. The alfalfa reference $\mathrm{ET}_{\mathrm{r}}$ is used in METRIC calibration (instead of $\mathrm{ET}_{\mathrm{o}}$ ) because $\mathrm{ET}_{\mathrm{r}}$ represents a near maximum limit on ET from full-cover vegetation. The ETrF is readily converted to $K_{\mathrm{c}}$ (grass-based crop coefficient) by multiplying by the $K_{\text {ratio, }}$ with $K_{\text {ratio }}=\mathrm{ET}_{\mathrm{r}} / \mathrm{ET}_{\mathrm{o}}$ (Allen et al., 1998, 2007b). The $\mathrm{ETr}_{\text {inst }}$ is commonly used to translate $\mathrm{ET}_{\text {inst }}$ to longer periods such as the day, assuming that the $\mathrm{ETrF}_{\text {inst }}$ is the same as the $24 \mathrm{~h}$ average ETrF (Allen et al., 2007b). This assumption, which has shown to be valid for agricultural crops developed to maximize photosynthesis and stomatal conductance (Allen et al., 2011b), needed correction for olive orchards. In fact, olive trees show an important stomatal control, closing stomata under conditions of high evaporative demand and widely opening stomata by the afternoon (Fernández et al., 1997; Moriana et al., 2002; Ramos and Santos, 2009). Thus, a decrease in ETrF during the part of the day when vapor pressure deficit was higher has been considered through adjusting ETrF during the mid-season as reported by Allen et al. (1998) for the grass-based crop coefficients. Therefore, in the mid-season period, when the vapour pressure deficit was higher, the translation of $\mathrm{ET}_{\text {inst }}$ into daily $\mathrm{ET}\left(\mathrm{ET}_{24}\right)$ was based upon an evaporation fraction, EF, according to the equation proposed by Allen et al. (2012).

$\mathrm{ET}_{24}=\mathrm{EF}\left(R_{\mathrm{n}}-G\right)_{24}$

with $\left(R_{\mathrm{n}}-G\right)_{24}$ corresponding to 24 h-periods of $R_{\mathrm{n}}$ and $G$, and $\mathrm{EF}$ being computed as the ratio between $\mathrm{ET}_{\text {inst }}$ and the difference
$R_{\mathrm{n}}-G$, thus $\mathrm{EF}=\mathrm{ET}_{\text {inst }} /\left(R_{\mathrm{n}}-G\right)$ (Hoedjes et al., 2008; Allen et al., 2011a). The use of EF for the satellite images of the mid-season period provided an appropriate adjustment for daily actual ETrF and daily ET (Pôças et al., 2014).

The METRIC model uses the CIMEC process (Calibration using Inverse Modeling at Extreme Conditions) for internal calibration of sensible heat flux (Allen et al., 2007b, 2012). Following this procedure, two "anchor points for calibration" - "cold pixel" and "hot pixel" - are selected to define the limit conditions for the energy balance over the study area. The cold pixel is selected and defined over an agricultural field well irrigated, non-stressed and at full cover, with ET corresponding to 1.05 of $\mathrm{ET}_{\mathrm{r}}$, thus representing maximum ET (Allen et al., 2007b). The hot pixel is selected and defined for a bare agricultural soil. The surface soil moisture was found, via soil water balance, to be dry enough for most of the image dates, then corresponding to a very small or null ET that allows to assume $H=R_{\mathrm{n}}-G$ for these hot pixels. However, for four image dates, precipitation occurred in the days prior to image capture, so $\mathrm{ET}_{\text {bare soil }}$ was then successfully estimated through a daily soil water balance of the surface layer, which was used to compute $H=R_{\mathrm{n}}-G-\mathrm{ET}_{\text {bare soil }}$ for the hot pixel (Allen et al., 2007b).

Meteorological data necessary to compute the soil water balance and $\mathrm{ET}_{\mathrm{r}}$ according to the ASCE procedure (Allen et al., 2005a) were collected at the Viana do Alentejo weather station as for computing $\mathrm{ET}_{\mathrm{o}}$. This weather station is considered to be a reference station based on the assessment procedures described by Allen et al. (1998). All weather data, including hourly wind speed, air temperature (maximum and minimum), solar radiation, relative humidity, and daily precipitation, were subjected to quality control following the procedures recommended by Allen et al. (1998).

METRIC is a one-source model, which considers soil and vegetation as a sole source in the estimation of ET by opposition to twosource models (Kustas et al., 2004; Timmermans et al., 2007). In sparse woody canopies, the estimation of $H$ may be biased by uncertainties in the definition of momentum roughness length and by the mixture and shading effects on the surface temperature and on the near-surface temperature gradient, dT; moreover, the estimation of pixel temperature may be biased by the soil and shadow effects (Allen et al., 2007b; Santos et al., 2012). Thus, because of the discontinuous ground cover conditions in olive orchards, some adjustments were adopted aimed at the estimation of the sensible heat flux for tall vegetation, the momentum roughness length, and vegetation temperature in tall canopies, which are described in detail by Pôças et al. (2014).

The estimation of $H$ in METRIC algorithm is done using an aerodynamic function that uses a near surface temperature difference $(\mathrm{dT})$ and an aerodynamic resistance, $\left(r_{\mathrm{ah} 1,2}\right)$ between two near surface heights $\left(z_{1}\right.$ and $z_{2}$ ) (Allen et al., 2011b). The parameter dT is determined at two extreme (cold and hot) conditions within the scene by inverse modeling of the energy balance, assuming that $\lambda E$ is near potential and near zero, respectively, at these extremes. Therefore, $\mathrm{dT}$ is determined by scaling instead of direct estimation of aerodynamic temperature (Allen et al., 2007b), assuming a relatively simple linear function between $\mathrm{dT}$ and the radiometric surface temperature $T_{\mathrm{s}}$ (Bastiaanssen et al., 1998). This assumption has proved to operate adequately over a large range of land use types and aerodynamic conditions (Bastiaanssen et al., 2005; Allen et al., 2007b). The $r_{\mathrm{ah} 1,2}$ is computed using the extrapolation of wind speed for some blending height above the surface and an iterative stability correction scheme based on the Monin-Obukhov functions (Monin and Obukhov, 1954). The dT and the aerodynamic resistance are estimated in a blended zone where dT and $r_{\mathrm{ah}}$ combine effects from both vegetation and soil surface (Allen et al., 2011b). Details on the computation of dT and $r_{\mathrm{ah}}$ in METRIC can be found in Allen et al. (2007b). 
In METRIC, the estimation of the momentum roughness length, $Z_{\mathrm{om}}$, is done for each pixel according to the land cover type or amount of vegetation. For tall vegetation, such as in orchards, the $Z_{\text {om }}$ may be estimated from crop height and LAI using the Perrier equation (Perrier, 1982). Advantages of adopting the Perrier equation, thus a $Z_{\mathrm{om}}$ that varies with crop density and height, as well as adjusting LAI and h estimates, are discussed by Pôças et al. (2014).

The canopies of tall vegetation integrate a mixture of different surfaces: sunlit and shaded canopy surfaces, along with sunlit and shaded soil surfaces. Thus, the surface temperature $T_{\mathrm{s}}$ observed by a satellite integrates a mixture of the temperatures of those surfaces, which are often different from each other. Thereby, the computation of the radiometric temperature for tall vegetation was modified to a three-source condition (Allen and Kjaersgaard, 2009):

$T_{\mathrm{s}}=f_{\mathrm{c}} T_{\mathrm{c}}+f_{\text {shadow }} T_{\text {shadow }}+f_{\text {sunlit }} T_{\text {sunlit }}$

where $f_{\mathrm{c}}, f_{\text {shadow }}$ and $f_{\text {sunlit }}$ correspond to the relative fraction of ground covered by vegetation, shadow and sunlit ground surface, respectively, when viewed from nadir, so that $f_{\mathrm{c}}+f_{\text {shadow }}+f_{\text {sunlit }}=1$. $T_{\mathrm{c}}, T_{\text {shadow }}$ and $T_{\text {sunlit }}$ are the temperatures of the canopy, the shaded ground surface and the sunlit ground surface, respectively. As the sunlit canopies are the primary source of energy exchange, the effective temperature for tall canopies can be estimated by solving Eq. (7) for $T_{\mathrm{c}}$. Hence, the canopy temperature used in the METRIC 'dT' function for sensible heat flux estimation is:

$T_{\mathrm{c}}=\left(T_{\mathrm{s}}-f_{\text {shadow }} T_{\text {shadow }}-f_{\text {sunlit }} T_{\text {sunlit }}\right) / f_{\mathrm{c}}$

$T_{\text {shadow }}$ and $T_{\text {sunlit }}$ are estimated as a function of the temperatures of the hot and cold pixels ( $T_{\text {hotpixel }}$ and $T_{\text {coldpixel }}$ ) and the temperature of the wet bulb ( $\left.T_{\text {wetbulb }}\right)$ as described by Allen and Kjaersgaard (2009). The $f_{\text {shadow }}$ and the $f_{\text {sunlit }}$ were estimated according to these authors. The estimation of the fraction of vegetation cover $\left(f_{\mathrm{c}}\right)$ for the olive orchard was based on the Normalized Difference Vegetation Index (NDVI) data and, for each pixel, was:

$f_{\mathrm{c}}=0.59\left(\mathrm{NDVI}_{i}-\mathrm{NDVI}_{\min }\right) /\left(\mathrm{NDVI}_{\max }-\mathrm{NDVI}_{\min }\right)+0.01$

where the $\mathrm{NDVI}_{i}$ is the NDVI for each pixel $i, \mathrm{NDVI}_{\min }$ and $\mathrm{NDVI}_{\max }$ are respectively the average minimum and maximum values of NDVI for a super high density olive orchard (set to 0.21 and 0.53 , respectively). The definition of maximum and minimum NDVI values was based on the analysis of the results of this vegetation index for the 16 image dates of 2011 and 2012. The improvements in METRIC performance due to the above described adjustments to a dense hedgerow olive orchard are discussed by Pôças et al. (2014) for this application.
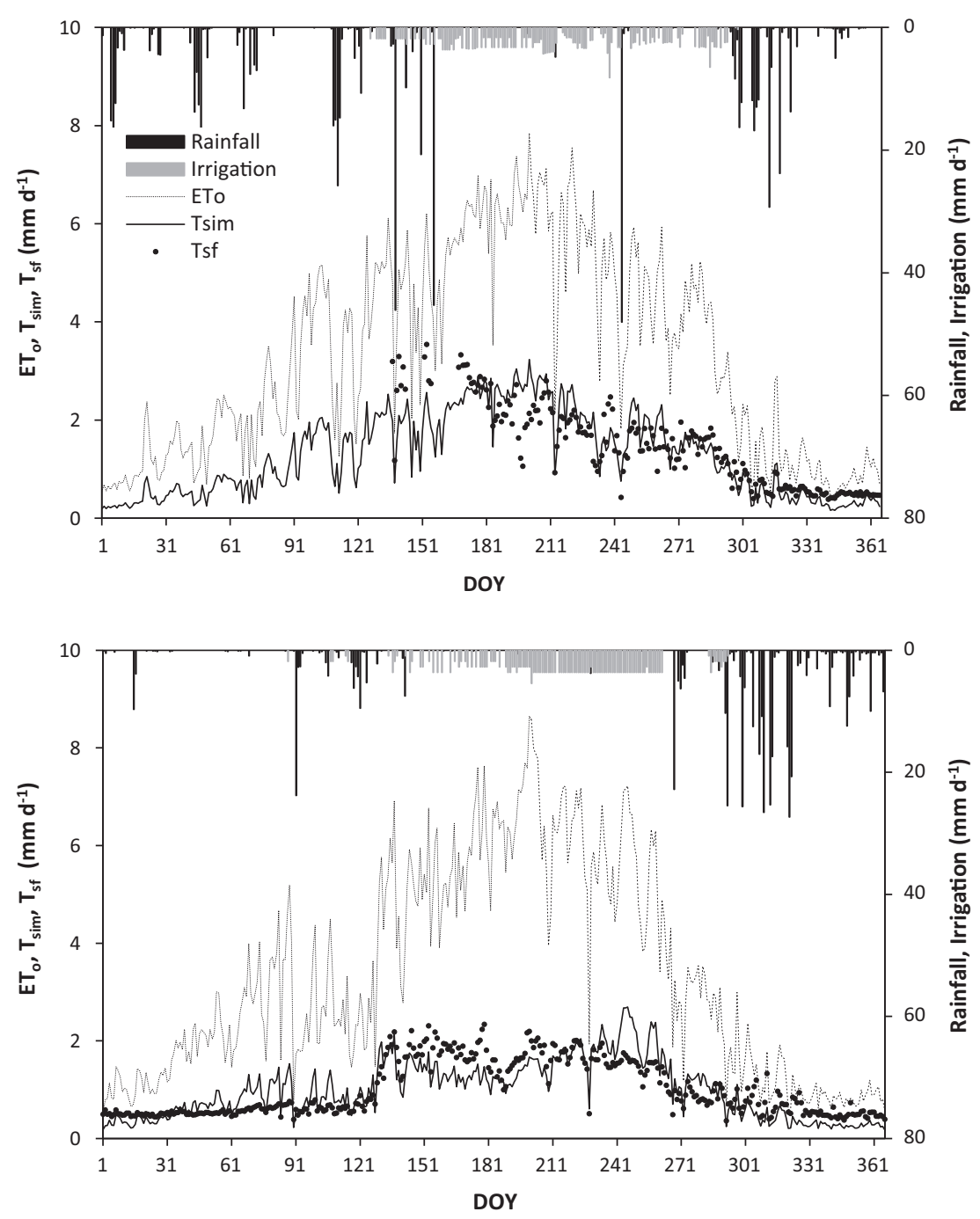

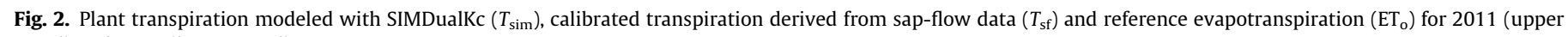
panel) and 2012 (lower panel). 
A digital elevation model was used to correct the surface temperature according to the differences in elevation and to produce slope and aspect maps required in METRIC to estimate solar radiation (Allen et al., 2007b, 2012). Further details of METRIC algorithm are given by Allen et al. (2007b, 2012). The software ERDAS IMAGINE v.2010 (Leica Geosystems) was used for the METRIC algorithm application.

\section{Results and discussion}

\subsection{Performance of SIMDualKc model calibrated with sap flow data}

The parameters that were mainly modified during calibration were $K_{\mathrm{cb}}$ and $p$. The values of all initial and calibrated parameters are presented in Table 2 . The $K_{\mathrm{cb}}$ used to initialize the model were $0.50,0.55$ and 0.50 respectively for the initial, mid-season and end season. These $K_{\mathrm{cb}}$ values were obtained for $M_{\mathrm{L}}=1.7$ (Eqs. (4) and (5)), thus lower than the initial value to reflect a plant canopy density and thickness closer to the lower limits usually considered. The final $K_{\mathrm{cb}}$ values are further analyzed in Section 3.4. The calibrated $p$ value $(0.4)$ was slightly lower than the standard one (0.5), which is likely due to the characteristics of the olive variety.

The comparison of transpiration data simulated by SIMDualKc with observed data, for almost two years, is shown in Fig. 2, which includes $\mathrm{ET}_{\mathrm{o}}$, rainfall and irrigation data. The data plots indicate that the model produces transpiration estimates close to observed data and no particular patterns of deviations are shown.

Related goodness of fit indicators are shown in Table 3 and allow to assume that SIMDualKc model performed well. For the calibration year (2011) observed and simulated transpiration data are well correlated, with a regression coefficient close to 1.0 ( $b=0.99$ ), thus indicating an excellent agreement between observed and simulated data sets of the model. In addition, the determination coefficient is high $\left(R^{2}=0.76\right)$, hence indicating that the model explains a large fraction of the data variance. RMSE and AAE indicators are low, 0.44 and $0.34 \mathrm{~mm} \mathrm{~d}^{-1}$, respectively. The modeling efficiency is good $(\mathrm{EF}=0.71)$ and $d_{\mathrm{IA}}$ is high (0.93), thus showing that the model simulated crop transpiration well for the calibration data set.

In 2012, the observed $\left(T_{\mathrm{sf}}\right)$ and estimated transpiration data $\left(T_{\text {sim }}\right)$ were again compared to validate the model and have shown to be well correlated (Table 3 ), however with a determination coefficient $R^{2}=0.65$ and a regression coefficient $b=0.95$ smaller that for the calibration. These results indicate a slight model underestimation but a reasonable explanation of data variance. However errors of estimates are smaller than for the calibration with RMSE $=0.35 \mathrm{~mm} \mathrm{~d}^{-1}$ and AAE $=0.28 \mathrm{~mm} \mathrm{~d}^{-1}$. The goodness of fit indicators $\left(\mathrm{EF}=0.60\right.$ and $\left.d_{\mathrm{IA}}=0.90\right)$ indicate a reasonably good performance of the model, with the variance of residuals much smaller than that of observations. Overall, goodness of fit data indicate a good performance of the model during validation, showing that the agreement between $T_{\text {sim }}$ and $T_{\text {sf }}$ was reasonably good, i.e., the SIMDualKc model shows to be able to simulate transpiration of an olive orchard, including for the period when the crop was largely affected by frost and heavy pruning in 2012 . A recently developed algorithm for automated correction of the sap-flow observations (Siqueira et al., 2014), which was developed and tested from observations performed within this study, was applied to part of data to improve $T_{\mathrm{sf}}$ data handling.

Mean modeled and observed transpiration (Table 4) were very similar in 2011 (1.3 and $1.5 \mathrm{~mm} \mathrm{~d}^{-1}$, respectively) and identical in $2012\left(1.0 \mathrm{~mm} \mathrm{~d}^{-1}\right)$. Minimum and maximum transpiration values in Table 4 were also quite close for both the calibration and validation years.

Table 4

Comparison of mean, maximum and minimum values of predicted $\left(\mathrm{ET}_{\mathrm{sim}}\right)$ and observed $\left(\mathrm{ET}_{\mathrm{obs}}\right)$ olive orchard evapotranspiration and transpiration $\left(T_{\mathrm{sim}}\right.$ and $\left.T_{\mathrm{sf}}\right)$.

\begin{tabular}{lllll}
\hline & $\mathrm{ET}_{\text {sim }}$ & $\mathrm{ET}_{\text {obs }}$ & $T_{\text {sim }}$ & $T_{\text {sf }}$ \\
\hline 2011 & & & & \\
Mean & 2.5 & - & 1.5 & - \\
Maximum & 6.5 & - & 3.9 & - \\
Minimum & 0.3 & - & 0.2 & - \\
2011 (DOY 137-365) & & & & \\
Mean & 2.2 & 2.4 & 1.3 & 1.5 \\
Maximum & 6.1 & 5.5 & 3.2 & 3.5 \\
Minimum & 0.3 & 0.5 & 0.2 & 0.4 \\
2012 & & & & \\
Mean & 1.7 & 1.7 & 1.0 & 1.0 \\
Maximum & 4.2 & 4.6 & 2.7 & 2.3 \\
Minimum & 0.2 & 0.4 & 0.2 & 0.4 \\
\hline
\end{tabular}

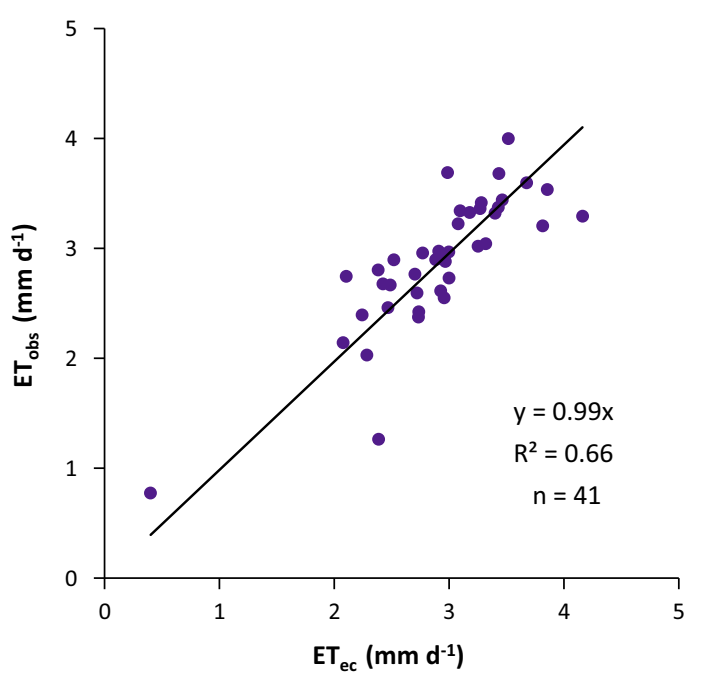

Fig. 3. Comparison between $\mathrm{ET}_{\mathrm{obs}}$ (observed data) and $\mathrm{ET}_{\mathrm{ec}}$ (eddy covariance data), 2011 and 2012.

Table 3

Goodness of fit indicators relative to SIMDualKc predicted transpiration values when compared with long time series derived from sap-flow observations.

\begin{tabular}{|c|c|c|c|c|c|c|c|c|c|}
\hline & $n$ & $b$ & $R^{2}$ & $\operatorname{RMSE}\left(\mathrm{mm} \mathrm{d}^{-1}\right)$ & $E_{\max }\left(\mathrm{mm} \mathrm{d}^{-1}\right)$ & $\mathrm{AAE}\left(\mathrm{mm} \mathrm{d}^{-1}\right)$ & ARE (\%) & $\mathrm{EF}$ & $d_{\mathrm{IA}}$ \\
\hline \multicolumn{10}{|c|}{ Calibration, 2011} \\
\hline$T_{\text {sim }}$ vs $T_{\mathrm{sf}}$ & 209 & 0.99 & 0.76 & 0.44 & 1.52 & 0.34 & 26.19 & 0.71 & 0.93 \\
\hline \multicolumn{10}{|c|}{ Validation, 2012} \\
\hline$T_{\text {sim }}$ vs $T_{\text {sf }}$ & 366 & 0.95 & 0.65 & 0.35 & 1.04 & 0.28 & 31.70 & 0.60 & 0.90 \\
\hline
\end{tabular}

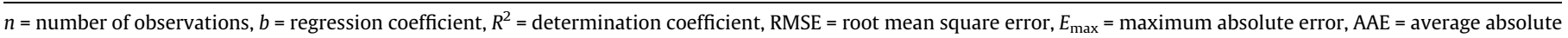
error, $\mathrm{ARE}=$ average relative error, $\mathrm{EF}=$ modeling efficiency, $d_{\mathrm{IA}}=$ index of agreement.

$T_{\text {sim }}$ and $T_{\text {sf }}$ are for transpiration respectively simulated with SIMDualKc and observed with sap-flow. 
3.2. Further model testing with eddy covariance and sap flow-based long-term series of evapotranspiration data

Evapotranspiration field-based data, $\mathrm{ET}_{\mathrm{ec}}$ and $\mathrm{ET}_{\mathrm{obs}}$, were compared by linear regression forced through the origin. $\mathrm{ET}_{\mathrm{ec}}$ and $\mathrm{ET}_{\mathrm{obs}}$ proved to be well correlated; results show only a very slight overestimation of $\mathrm{ET}_{\mathrm{ec}}\left(\mathrm{ET}_{\mathrm{obs}}=0.99 \mathrm{ET}_{\mathrm{ec}}, R^{2}=0.66, n=41\right.$, Fig. 3$)$.

SIMDualKc model estimations of $\mathrm{ET}_{\mathrm{c} \text { adj }}\left(\mathrm{ET}_{\mathrm{sim}}\right)$ were compared with field data in two steps: in the first, $\mathrm{ET}_{\text {sim }}$ was compared with eddy covariance $\mathrm{ET}_{\mathrm{ec}}$; in the second, $\mathrm{ET}_{\text {sim }}$ was compared with $\mathrm{ET}_{\mathrm{obs}}$ (Eq. (1)). In the first step, $\mathrm{ET}_{\mathrm{ec}}$ varied between 2.2 and $4.2 \mathrm{~mm} \mathrm{~d}^{-1}$ in 2011 (July-August, $n=13$ ) and 0.4 and $3.5 \mathrm{~mm} \mathrm{~d}^{-1}$ in 2012 (June-August, $n=28$ ). For the same time intervals, $\mathrm{ET}_{\text {sim }}$ ranged between 1.2 and $4.4 \mathrm{~mm} \mathrm{~d}^{-1}$ and 0.8 and $3.3 \mathrm{~mm} \mathrm{~d}^{-1}$, respectively (Fig. 4). For the first year (2011), the number of days with $\mathrm{ET}_{\mathrm{ec}}$ data is not large enough to perform a goodness of fit analysis. Differently, in 2012 observed ( $\mathrm{ET}_{\mathrm{ec}}$ ) and estimated ET data have shown to be well correlated, with a determination coefficient $R^{2}=0.71$ (Table 5) and a regression coefficient $b=0.92$, thus indicating a trend for model underestimation relative to the eddy covariance results. Nevertheless, RMSE was small $\left(0.37 \mathrm{~mm} \mathrm{~d}^{-1}\right)$ and the relative error was only $15.1 \% \mathrm{EF}=0.57$ and $d_{\mathrm{IA}}=0.88$ indicate that the agreement between $\mathrm{ET}_{\text {sim }}$ and $\mathrm{ET}_{\mathrm{ec}}$ were acceptable. However, the number of paired observations was quite small $(n=28)$.

The second step of testing compared $\mathrm{ET}_{\text {sim }}$ with $\mathrm{ET}_{\text {obs. }}$. The latter used long series of $T_{\mathrm{sf}}$ and $E_{\mathrm{s}} \operatorname{sim}$. The $E_{\mathrm{s}}$ sim were simulated by the
Ritchie's model for soil evaporation (Ritchie, 1972), the same model adopted in SIMDualKc model. This fact introduces some dependency among variables but this dependency is partially overcome because $E_{\mathrm{s}}$ is the smallest component of ET, with the ratio of $E_{\mathrm{s} \text { sim }}$ to $\mathrm{ET}_{\text {sim }}$ generally not exceeding 0.3 throughout the year. Despite the number of days with measured $E_{\mathrm{s}}$ data is small $(n=8)$, it was observed that simulated data $\left(E_{\mathrm{s}}\right.$ sim $)$ are close to observed $E_{\mathrm{s}}$ (Fig. 5). This results are in agreement with those obtained for a peach orchard (Paço et al., 2012), and for wheat, maize and soybeans (Zhao et al., 2013; Wei et al., 2014), hence allowing to assume the goodness of $E_{\mathrm{s}} \operatorname{sim}$ for operational purposes. Thus, it was possible to obtain a series of $\mathrm{ET}_{\mathrm{obs}}$ with the same length as $T_{\mathrm{sf}}$ by adding to these observed transpiration values the soil evaporation values simulated with the Ritchie's model, $E_{\mathrm{s} \text { sim. }}$ Considering the limited data available for $\mathrm{ET}_{\mathrm{ec}}$ referred before, using $\mathrm{ET}_{\mathrm{obs}}$ allows further assessing the operational results of SIMDualKc, $\mathrm{ET}_{\text {sim }}$, throughout the year.

When comparing $\mathrm{ET}_{\text {sim }}$ with $\mathrm{ET}_{\mathrm{obs}}$ in 2011, for the period with available sap-flow data (DOY 137-365), $\mathrm{ET}_{\text {sim }}$ agreed well with field derived data $\left(\mathrm{ET}_{\mathrm{obs}}\right)$ as shown in Fig. 5 and Table 5. Mean observed and simulated ET for this time period are very close, 2.4 and $2.2 \mathrm{~mm} \mathrm{~d}^{-1}$, respectively (Table 4). Observed and simulated data are well correlated $\left(R^{2}=0.88\right)$ with a regression coefficient equal to 1.0 , thus indicating a good agreement between data derived from observations and simulated by the model. The RMSE and AAE indicators are 0.44 and $0.34 \mathrm{~mm} \mathrm{~d}^{-1}$, respectively
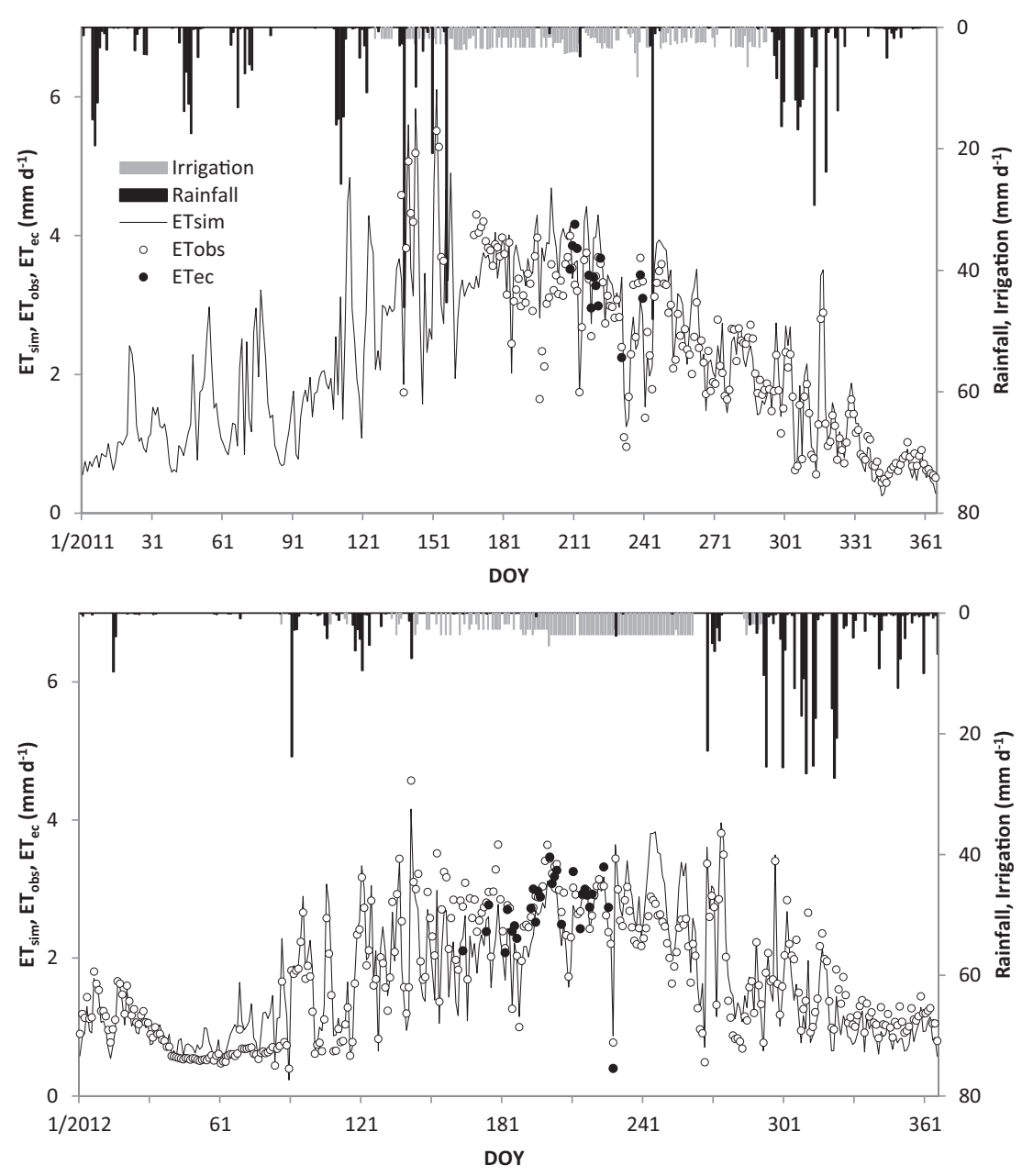

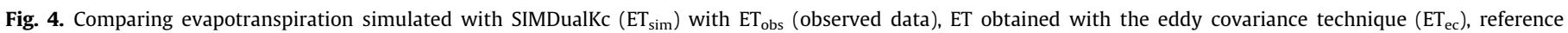
evapotranspiration ( $\mathrm{ET}_{\mathrm{o}}$ ), rainfall and irrigation for 2011 (upper panel) and 2012 (lower panel). 
Table 5

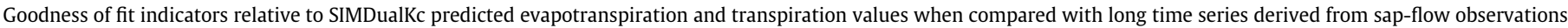
or eddy covariance measurements.

\begin{tabular}{|c|c|c|c|c|c|c|c|c|c|}
\hline & $n$ & $b$ & $R^{2}$ & $\operatorname{RMSE}\left(\mathrm{mm} \mathrm{d}^{-1}\right)$ & $E_{\max }\left(\mathrm{mm} \mathrm{d}^{-1}\right)$ & $\operatorname{AAE}\left(\mathrm{mm} \mathrm{d}^{-1}\right)$ & ARE (\%) & $\mathrm{EF}$ & $d_{\mathrm{IA}}$ \\
\hline \multicolumn{10}{|l|}{ Testing, 2011} \\
\hline $\mathrm{ET}_{\text {sim }}$ vs $\mathrm{ET}_{\mathrm{obs}}$ & 209 & 1.00 & 0.88 & 0.44 & 1.52 & 0.34 & 15.48 & 0.87 & 0.97 \\
\hline \multicolumn{10}{|l|}{ Testing, 2012} \\
\hline $\mathrm{ET}_{\text {sim }} \mathrm{vs} \mathrm{ET}_{\mathrm{ec}}$ & 28 & 0.92 & 0.71 & 0.37 & 1.09 & 0.31 & 15.10 & 0.57 & 0.88 \\
\hline $\mathrm{ET}_{\text {sim }} \mathrm{vs} \mathrm{ET}_{\mathrm{obs}}$ & 366 & 0.97 & 0.85 & 0.35 & 1.04 & 0.28 & 20.51 & 0.84 & 0.96 \\
\hline
\end{tabular}

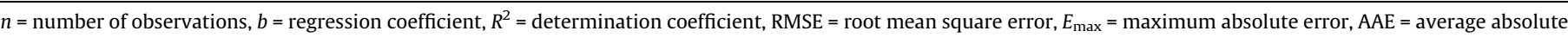
error, $\mathrm{ARE}=$ average relative error, $\mathrm{EF}=$ modeling efficiency, $d_{\mathrm{IA}}=$ index of agreement.

$\mathrm{ET}_{\text {sim }}, \mathrm{ET}_{\mathrm{ec}}$ and $\mathrm{ET}_{\mathrm{obs}}$ are respectively evapotranspiration simulated with SIMDualKc, and derived from eddy covariance and from sap-flow measurements.
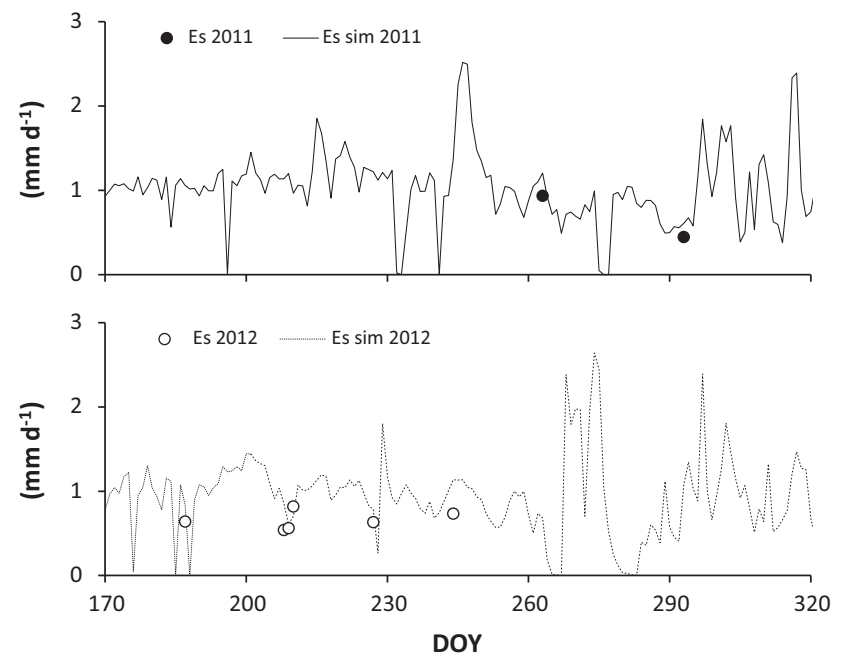

Fig. 5. Soil evaporation modeled with SIMDualKc $\left(E_{\mathrm{s}}\right.$ sim $)$ and measured with microlysimeters $\left(E_{\mathrm{s}}\right)$; peaks are due to intensive rainfall.

and the relative error of estimates is small (ARE $=15.48 \%$ ). In addition, the modeling efficiency is good $(E F=0.87)$. The index of agreement is very high $\left(d_{\mathrm{IA}}=0.97\right)$, thus showing the mean square error is close to the potential error of model estimation. In 2012 $\mathrm{ET}_{\text {sim }}$ and $\mathrm{ET}_{\mathrm{obs}}$ had the same average, $1.7 \mathrm{~mm} \mathrm{~d}^{-1}$ (Table 4). As shown in Fig. 3 the $\mathrm{ET}_{\text {sim }}$ values follow a similar pattern to $\mathrm{ET}_{\mathrm{obs}}$. The goodness of fit evaluated through their regression forced to the origin provided $R^{2}=0.85$ and $b=0.97$ (Table 5), thus also indicating that most of the variance is explained by the model and that a good agreement exists between both sets of data. The errors of estimates indicated by the RMSE and AAE results are smaller than for $2011,0.35$ and $0.28 \mathrm{~mm} \mathrm{~d}^{-1}$ respectively, but ARE is higher, $20.5 \%$, which relates to the fact that in 2012 the canopy characteristics changed due to a heavy frost and a heavy pruning. EF and $d_{\mathrm{IA}}$, respectively 0.84 and 0.96 , are similar to those obtained for 2011 . Overall, these results show a good performance of the model at testing.

Comparing the results obtained for $\mathrm{ET}_{\text {sim }}$ with both $\mathrm{ET}_{\mathrm{ec}}$ and $\mathrm{ET}_{\mathrm{obs}}$, it can be observed that the goodness of fit indicators are better for $\mathrm{ET}_{\mathrm{obs}}$ despite errors are quite similar (Table 5). This is likely due to the number of observations, $n=28$, for the EC data series and $n=366$ for the data set built from $T_{\mathrm{sf}}$. A large $n$ tends to decrease the size of the variances compared in EF and $d_{\mathrm{IA}}$, as well as the errors of estimates. The smaller relative error ARE for the comparison with $\mathrm{ET}_{\mathrm{ec}}$ is due to the fact that related observations refer to a period of high ET while $\mathrm{ET}_{\text {obs }}$ values cover the full year, thus with a mean value much smaller than the former. Nevertheless, model testing with both $\mathrm{ET}_{\mathrm{ec}}$ and $\mathrm{ET}_{\mathrm{obs}}$ confirm the goodness of results obtained with the calibration and validation using transpiration data.

\subsection{ET derived from METRIC and satellite data}

The results of ET derived from METRIC (ET METRIC $_{\text {) to the super }}$ intensive olive orchard were compared with ET derived from ground data and from SIMDualKc (Fig. 6). The $\mathrm{ET}_{\text {METRIC }}$ results correspond to an average value of all the pixels of the olive orchard, excluding the pixels representing roads or buildings within the orchard, while ground data correspond to punctual values and local measurements within the orchard.

The values of $\mathrm{ET}_{\text {METRIC }}$ ranged between $1.5 \mathrm{~mm} \mathrm{~d}^{-1}$ in January and $6.0 \mathrm{~mm} \mathrm{~d}^{-1}$ in May in 2011, and between $0.9 \mathrm{~mm} \mathrm{~d}^{-1}$ in February and $4.5 \mathrm{~mm} \mathrm{~d}^{-1}$ in July in 2012 (Fig. 6). The mean bias between $\mathrm{ET}_{\text {METRIC }}$ and ET derived from field data ( $\mathrm{ET}_{\mathrm{obs}}$ ) was $20 \%$ for the set of dates studied in both years, excluding DOY 282 from 2012, whose results were considered unacceptable due to problems in ET estimation.

For the year 2011, the mean bias between $\mathrm{ET}_{\text {METRIC }}$ and $\mathrm{ET}_{\text {obs }}$ was $12.6 \%$ (corresponding to a mean absolute difference of $0.4 \mathrm{~mm} \mathrm{~d}^{-1}$ ), with the larger difference ( $29 \%$ of bias, representing an absolute difference of $0.8 \mathrm{~mm} \mathrm{~d}^{-1}$ ) occurring for the image date of October 6th (DOY 279). For the year 2012, the mean bias was larger, 31.2\%, corresponding to a mean absolute difference of $0.6 \mathrm{~mm} \mathrm{~d}^{-1}$. For this year, the maximum absolute difference between $\mathrm{ET}_{\text {METRIC }}$ and $\mathrm{ET}_{\text {obs }}$ was $1.2 \mathrm{~mm} \mathrm{~d}^{-1}$ (July 20th, DOY 202). When comparing the standard deviation (SD) relative to the $\mathrm{ET}_{\mathrm{METRIC}}$ results for all the pixels of the olive orchard, the values ranged between 0.19 and $0.50 \mathrm{~mm} \mathrm{~d}^{-1}$ in 2011 and between 0.31 and $0.82 \mathrm{~mm} \mathrm{~d}^{-1}$ in 2012. Such results indicate that the larger mean bias in 2012 is most likely due to the larger spatial variability of the vegetation within the orchard due to the mentioned frost occurrence and subsequent non-uniform heavy pruning. These changes in canopy architecture were not uniform throughout the orchard but largely varied spatially, as emphasized by the comparison of SD results for both years as discussed by Pôças et al. (2014). Moreover, the overall discrepancies between $\mathrm{ET}_{\text {METRIC }}$ and $\mathrm{ET}_{\text {obs }}$ can also be due to the limitations of applying a

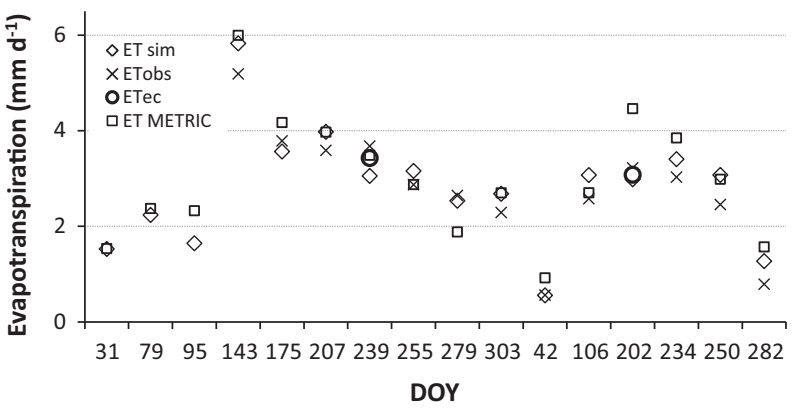

Fig. 6. Daily Evapotranspiration modeled with SIMDualKc $\left(\mathrm{ET}_{\text {sim }}\right)$, ET derived from ground data $\left(\mathrm{ET}_{\mathrm{obs}}\right)$, ET obtained with the eddy covariance technique $\left(\mathrm{ET}_{\mathrm{ec}}\right), \mathrm{ET}$ derived from METRIC ( $\mathrm{ET}_{\text {METRIC }}$ ) and reference evapotranspiration ( $\mathrm{ET}_{\mathrm{o}}$ ) for 2011 and 2012. 
one-source surface energy balance (SEB) model like METRIC to crops with a discontinuous ground cover. In theory, two-source SEB models like TSEB, which allow differentiating soil and vegetation components in the computation of the energy balance, perform better than one-source SEB models in discontinuous woody crops (Minacapilli et al., 2009; Timmermans et al., 2007). However, the data required to parameterize and apply TSEB are often not readily available. Nevertheless, the adopted computation of surface temperature using a three source condition helps overcoming the limitation of a onesource model, as discussed by Pôças et al. (2014). The results obtained in the current study agree with those reported by Bastiaanssen et al. (2008) for applications of the one-source model SEBAL to several tree crops with mean biases ranging from $2.5 \%$ to $24.6 \%$.

The comparison of the results derived from METRIC and SIMDualKc for the set of image dates considered showed that $\mathrm{ET}_{\text {METRIC }}$ and $\mathrm{ET}_{\text {sim }}$ follow a similar pattern (Fig. 6). The overall mean bias between $\mathrm{ET}_{\text {METRIC }}$ and $\mathrm{ET}_{\text {sim }}$ was $18 \%$, corresponding to a mean absolute difference of $0.4 \mathrm{~mm} \mathrm{~d}^{-1}$. For the year 2011, the mean bias between ET derived from both models was $11.2 \%$ (or $0.3 \mathrm{~mm} \mathrm{~d}^{-1}$ ), with a maximum absolute difference of $0.7 \mathrm{~mm} \mathrm{~d}^{-1}$ (DOY 95), while for 2012 the mean bias was $27.8 \%$ (or $0.5 \mathrm{~mm} \mathrm{~d}^{-1}$ ) with a maximum absolute difference of $1.48 \mathrm{~mm} \mathrm{~d}^{-1}$ (DOY 202).

\subsection{Comparison of crop coefficients derived from SIMDualKc and METRIC}

The basal crop coefficients values (vd. Section 3.1) are similar to those proposed by Allen and Pereira (2009) for olive orchards with $f_{\mathrm{c}}=0.50$. Fig. 7 presents the $K_{\mathrm{cb}}$ curve, adjusted by the SIMDualKc model to climate (Allen et al., 1998) and to plant density, thus with
$K_{\mathrm{d}}$ approximately 0.6 , to reflect the canopy density and vigor of the surface coverage (Allen and Pereira, 2009). The $K_{\mathrm{cb} \text { mid }}$ and $K_{\mathrm{cb}}$ end resulted in lower values than the standard ones. For $2011, K_{\mathrm{cb}}$ mid and $K_{\mathrm{cb}}$ end values decreased respectively to 0.41 and 0.34 and, in 2012 , to 0.38 and 0.31 , resulting from a strong leaf fall and a heavy pruning (Fig. 7). The $K_{\mathrm{cb}}$ ini values were 0.36 and 0.33 , in 2011 and 2012 , respectively. The lower value in the second year reflects the frost occurrence and a consequent decrease in vegetative growth.

Fig. 7 also presents the $K_{\mathrm{e}}$ curve and the adjusted $K_{\mathrm{c}}$ curve $\left(K_{\mathrm{c} \text { adj }}\right)$. The $K_{\mathrm{c} \text { adj }}$ curve is the result of the daily sum of $K_{\mathrm{e}}$ with the $K_{\mathrm{cb} \text { adj }}$; the latter represents the $K_{\mathrm{cb}}$ values adjusted for water stress $\left(K_{\mathrm{cb} \text { adj }}=K_{\mathrm{s}} K_{\mathrm{cb}}\right)$. The $K_{\mathrm{e}}$ shows for both years several peaks resulting mainly from precipitation events. After full canopy development, by the mid-season, less energy is available at the soil surface for evaporation and the fraction of wetted soil is lower (only wetted by irrigation), thus $K_{\mathrm{e}}$ values remain low. $K_{\mathrm{cb}}$ adj curve lays below $K_{\mathrm{cb}}$ curve during the stress periods. In 2011, this occurred for two short periods of time (217-241, 262-296); differently, for 2012 the stress occurred for a wider period (131-242).

The mean $K_{\mathrm{c} \text { adj }}$ values during the spring-summer period (Fig. 7) were 0.59 and 0.49 in 2011 and 2012, respectively. The lower $K_{\text {c adj }}$ values during 2012 reflect the lower canopy density and also water stress that occurred during the period. During the rainy season, $K_{\mathrm{c}}$ adj ini values were higher, ranging from 0.63 to 0.81 and $K_{\mathrm{c}}$ adj end were 0.95 to 1.06 , which reflected a high number of rainfall events that increased $E_{\mathrm{s}}$. These results indicate that $K_{\mathrm{c}}$ adj is much higher during the rainy season than $K_{\mathrm{c}}$ adj mid during the summer season.

The daily crop coefficients derived from METRIC $\left(K_{\mathrm{c} \text { METRIC }}\right)$ ranged from 0.40 to 1.20 in 2011 and from 0.47 to 0.74 in 2012 (Fig. 8), while the $K_{\mathrm{c}}$ obtained with SIMDualKc $\left(K_{\mathrm{c} \text { adj }}\right)$ ranged between 0.31 and 1.24 in 2011 and between 0.18 and 1.17 in 2012 .
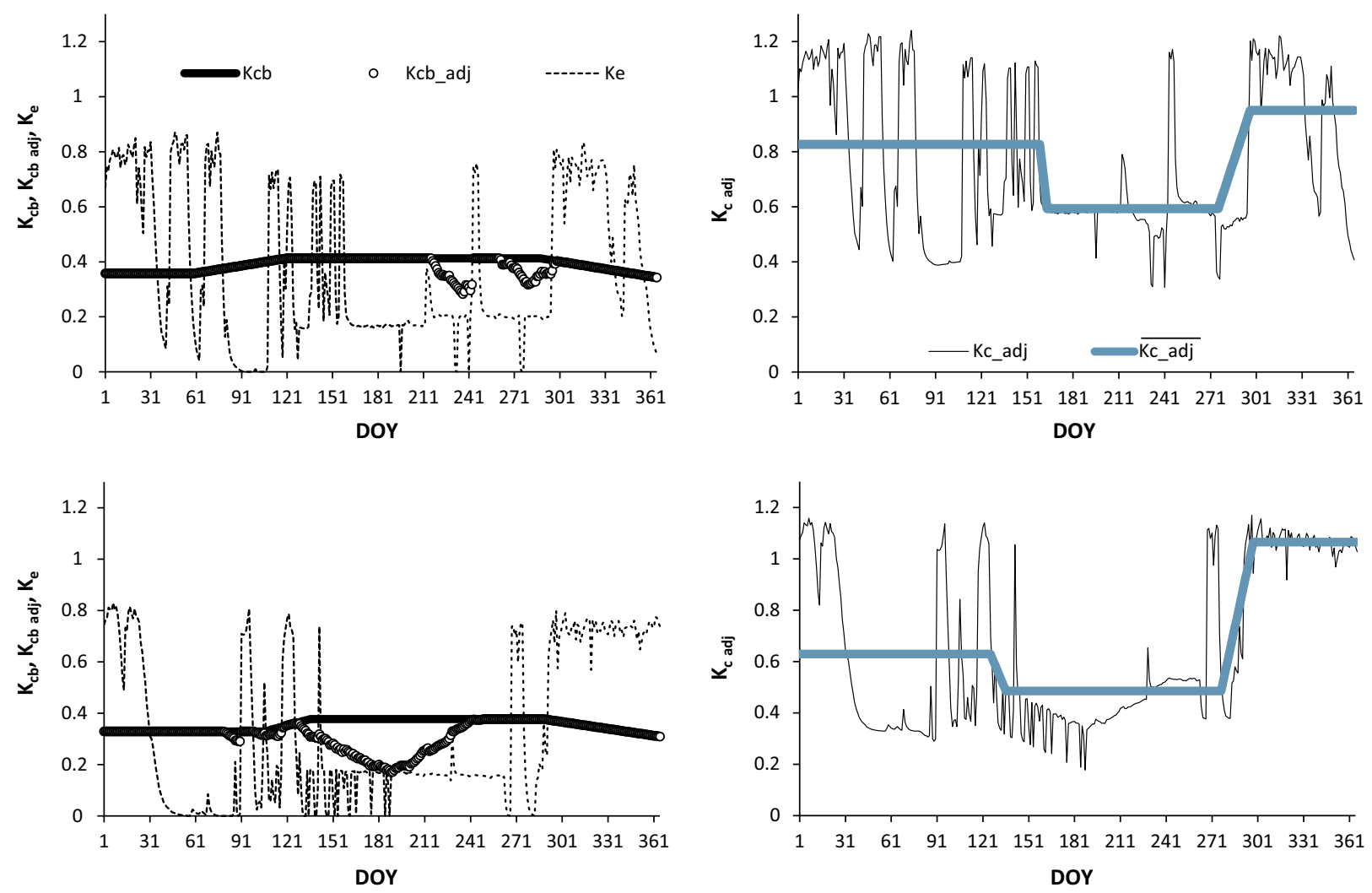

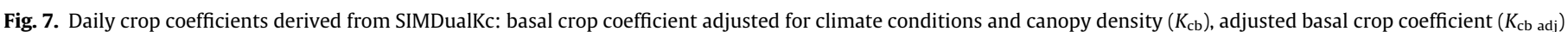

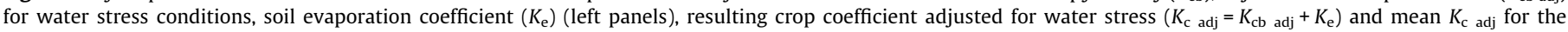
different growth stages (right panels), in the years 2011 (upper panels) and 2012 (lower panels). 


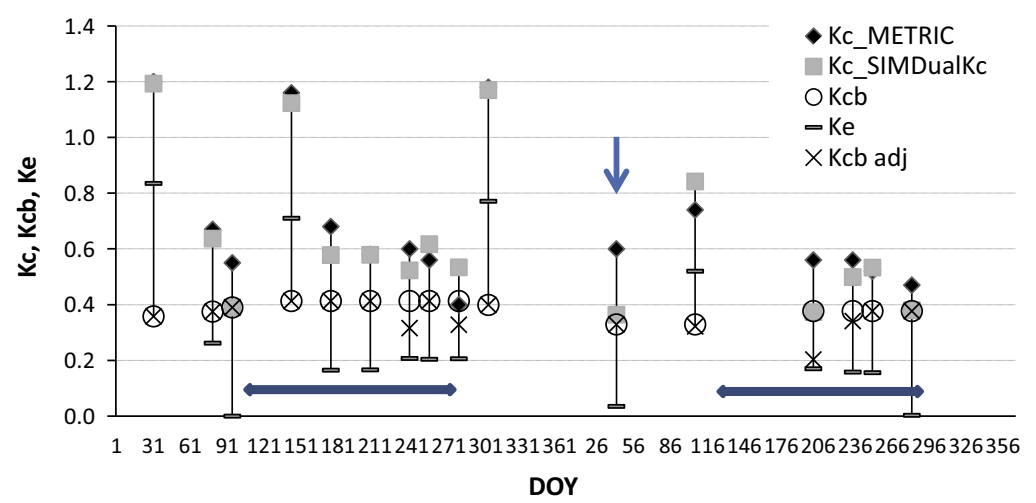

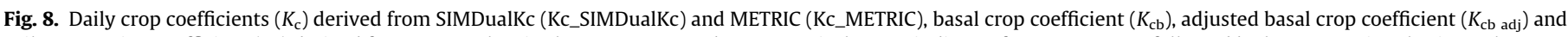

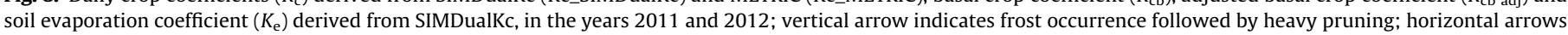
indicate the mid season of crop development.

The results of crop coefficients derived from both models follow a similar pattern (Fig. 8), and present a high correlation, with a determination coefficient of 0.86 and a regression coefficient of 0.99 (data not shown). The results for 2011, from both models, showed higher $K_{\mathrm{c}}$ values during winter and autumn image dates (Fig. 8 upper panel). The higher $K_{\mathrm{c}}$ values during this period of the year (image dates from January 31st - DOY 31, and October 30th - DOY 303), as well as in the May 23rd image (DOY 143), result from an increase in soil evaporation due to precipitation occurrence. For other dates considered, as the precipitation occurrence decreased and the soil was less wet, $K_{\mathrm{c}}$ was lower and less variable, with values around 0.6. During the summer dry period $K_{\mathrm{c}}$ values are mainly relative to transpiration and consequently due to olive green cover. As observed for SIMDualKc results, these results are consistent with those of Villalobos et al. (2000), indicating that $K_{\mathrm{c}}$ includes the effect of rainfall on soil evaporation and therefore tends to be higher during the rainy seasons, and also with the ones obtained by Testi et al. (2004, 2006b). These authors found, for a drip irrigated intensive olive orchard, higher $K_{\mathrm{c}}$ values (close to 1) occurring in the wet season and decreasing in the summer period. The $K_{\mathrm{c}}$ values obtained in this study also follow a similar pattern throughout the year to the one obtained by Santos et al. (2012) for a rainfed olive orchard. Nevertheless, values obtained for the studied irrigated orchard are higher than the values reported by Santos et al. (2012) because of irrigation and plant density (up to 200 vs 1975 trees ha ${ }^{-1}$ ). $K_{\mathrm{c}}$ results obtained by both models are also similar to the $K_{\mathrm{c}}$ values for olive orchards with an effective fraction of ground cover $\left(f_{\mathrm{c}}\right.$ eff $)$ between 0.25 and 0.5 published by Allen and Pereira (2009), which vary between 0.80 for the $K_{\mathrm{c}}$ ini (considering an active ground cover), $0.40-0.60$ for the $K_{\mathrm{c} \text { mid }}$ (no active ground cover), and $0.35-0.75$ for the $K_{\mathrm{c}}$ end (depending on the ground cover).

The lower $K_{c}$ values obtained for the images of 2012 (Fig. 8 lower panel) are likely due to the severe frost occurrence during winter period followed by an intensive pruning aimed at overcoming the frost damages, which had impact on $K_{\mathrm{d}}$. In 2012, $K_{\mathrm{d}}$ minimum values were lower (close to 0.17) than in 2011 (ca. 0.39), although mean yearly $K_{\mathrm{d}}$ values were similar (around 0.60). Moreover, the precipitation occurrence in 2012 was much lower than in 2011 (Table 1). The comparison of the results obtained in 2011 and 2012 show that the interannual variability in precipitation occurrence lead to changes in $K_{\mathrm{c}}$ (Fig. 7), particularly during the winter and autumn seasons. Additionally, the comparison of the results of both years shows that crop management practices like pruning, which impact LAI and canopy architecture and condition, affect $K_{\mathrm{c}}$, and other abiotic stresses such as severe frost occurrence also impact those values.
As discussed, the $K_{\mathrm{c}}$ values derived from both models follow a similar pattern (Fig. 8). The mean bias between values of $K_{\text {c METRIC }}$ and $K_{c \text { adj }}$ for the set of dates considered was $18 \%$ (12\% in 2011 and $28 \%$ in 2012). In 2011, the larger biases were observed for the image dates of April 5th (DOY 95) and October 6th (DOY 279), with an absolute difference of 0.16 and 0.14 respectively (Fig. 8 left panel). For the year 2012 the larger biases were observed for the images dates of February 11th (DOY 42) and July 20th (DOY 202), corresponding to an absolute difference of 0.24 and 0.19 respectively (Fig. 8 right panel).

\section{Conclusions}

The main objective of the present study was the computation and analysis of olive crop evapotranspiration and the determination of crop coefficients from ground and satellite observations, respectively using the SIMDualKc model and the METRIC algorithm. Good results were obtained for the comparison between ET derived from SIMDualKc and from ground data. In addition, the possibility of simulating evapotranspiration components per se contributed to the understanding of the crop functioning, namely relative to the role of soil evaporation, which greatly varies along the year. Adopting the dual $K_{\mathrm{c}}$ approach, it was observed that the basal crop coefficient $K_{\mathrm{cb}}$ changed little throughout the year and from one year to the next, having higher values during the spring-summer period. Differently, the evaporation coefficient $K_{\mathrm{e}}$ greatly changes throughout the year and has higher values during the rainy season and quite low values during the dry season. The resulting $K_{\mathrm{c}}$ average values therefore show a pattern different of that common for most crops, with higher values in the cold rainy season and lower values during the active growing spring-summer season.

The results obtained show that the $K_{\mathrm{c}}$ in olive orchards is affected by several factors including the canopy architecture, the fraction of ground covered by the vegetation, crop management practices and rainfall variability. The incomplete ground cover associated with this type of evergreen crop increases the relative importance of the soil evaporation component particularly during the rainy season. This fact leads to a $K_{\mathrm{c}}$ pattern with maximum values in late autumn, winter and early spring, and lower values in the summer period, when the soil evaporation decreases and evapotranspiration is mainly determined by transpiration.

The $K_{\mathrm{c}}$ obtained from both models are consistent and in agreement. The crop coefficient simulation procedure as a function of the fraction of ground cover and plant height used in SIMDualKc proved to be an adequate approach to the olive crop. Additionally, 
the results from METRIC allowed obtaining information about the spatial variability of ET within the olive orchard. The results obtained from both models revealed good perspectives for the use of $K_{\mathrm{c}}$ information derived from the METRIC algorithm as inputs to models like SIMDualKc, thus to improve the definition of actual $K_{c}$ values considering the specificities of vegetation architecture and the spatial variability within orchards. The two models are complementary, using very distinct approaches, yet leading to comparable results, which is a relevant feature demonstrated. Nevertheless, further tests applied to larger time series are needed to further improve knowledge on ET from super high density olive orchards. In addition, a rainfall interception module needs to be developed for SIMDualKc aiming at better represent the hydrologic processes involved.

\section{Acknowledgments}

This study was supported by the Projects PTDC/AGR-PRO/ $111717 / 2009$ and EXPL/AGR-PRO/1559/2012 funded by "Fundação para a Ciência e a Tecnologia", Portugal. The second author also acknowledges the same institution for the Post-Doc research Grant (SFRH/BPD/79767/2011). Thanks are due to Dr. Richard G. Allen for making available the METRIC algorithm and related developments, and advising on its application. Developments of the METRIC processing algorithms were supported by Idaho Agricultural Experiment Station, Idaho Department of Water Resources, the US Geological Survey, NASA, the National Science Foundation EPSCoR Program EPS-0814387, and Raytheon Company.

\section{References}

Abazi, U., Lorite, I.J., Carceles, B., Raya, A.M., Duran, V.H., Francia, J.R., Gómez, J.A. 2013. WABOL: a conceptual water balance model for analyzing rainfall water use in olive orchards under different soil and cover crop management strategies. Comput. Electron. Agric. 91, 35-48.

Aïachi Mezghani, M., Charfi, C.M., Gouiaa, M., Labidi, F., 2012. Vegetative and reproductive behaviour of some olive tree varieties (Olea europaea L.) unde deficit irrigation regimes in semi-arid conditions of Central Tunisia. Sci. Hortic. 146, 143-152.

Allen, R.G., Kjaersgaard, J., 2009. An Algorithm to Estimate Vegetation Temperature in Canopies for Tall Vegetation. Interoffice memo. University of Idaho, Idaho.

Allen, R.G., Pereira, L.S., 2009. Estimating crop coefficients from fraction of ground cover and height. Irrig. Sci. 28, 17-34.

Allen, R.G., Pereira, L.S., Raes, D., Smith, M., 1998. Crop Evapotranspiration: Guidelines for Computing Crop Water Requirements. FAO Irrigation and drainage paper 56 FAO - Food and Agriculture Organization of the United Nations, Rome, Italy.

Allen, R., Pereira, L., Smith, M., Raes, D., Wright, J., 2005a. FAO-56 dual crop coefficient method for estimating evaporation from soil and application extensions. J. Irrig. Drain. Eng. 131, 2-13.

Allen, R.G., Walter, I.A., Elliott, R.L., Howell, T.A., Itenfisu, D., Jensen, M.E., Snyder, R.L., 2005b. The ASCE Standardized Reference Evapotranspiration Equation. ASCE-American Society of Civil Engineers, New York.

Allen, R.G., Tasumi, M., Morse, A., Trezza, R., Wright, J.L., Bastiaanssen, W., Kramber, W., Lorite, I., Robison, C.W., 2007a. Satellite-based energy balance for mapping evapotranspiration with internalized calibration (METRIC) - applications. J. Irrig. Drain. Eng. 133, 395-406.

Allen, R.G., Tasumi, M., Trezza, R., 2007b. Satellite-based energy balance for mapping evapotranspiration with internalized calibration (METRIC) - model. J Irrig. Drain. Eng. 133, 380-394.

Allen, R.G., Wright, J.L., Pruitt, W.O., Pereira, L.S., Jensen, M.E., 2007c. Water requirements. In: Hoffman, G.J., Evans, R.G., Jensen, M.E., Martin, D.L., Elliot, R.L. (Eds.), Design and Operation of Farm Irrigation Systems, second ed., ASABE, St. Joseph, MI, pp. 208-288.

Allen, R., Irmak, A., Trezza, R., Hendrickx, J.M.H., Bastiaanssen, W., Kjaersgaard, J., 2011a. Satellite-based ET estimation in agriculture using SEBAL and METRIC. Hydrol. Process. 25, 4011-4027.

Allen, R.G., Pereira, L.S., Howell, T.A., Jensen, M.E., 2011b. Evapotranspiration information reporting: I. Factors governing measurement accuracy. Agric. Water Manage. 98, 899-920.

Allen, R.G., Trezza, R., Tasumi, M., Kjaersgaard, J., 2012. METRIC Mapping Evapotranspiration at High Resolution. Applications Manual for Landsat Satellite Imagery. Version 2.0.8. University of Idaho, Kimberly, Idaho.

Anderson, M.C., Allen, R.G., Morse, A., Kustas, W.P., 2012. Use of Landsat thermal imagery in monitoring evapotranspiration and managing water resources. Remote Sens. Environ. 122, 50-65.
Bastiaanssen, W.G.M., 2000. SEBAL-based sensible and latent heat fluxes in the irrigated Gediz Basin, Turkey. J. Hydrol. 229, 87-100.

Bastiaanssen, W.G.M., Menenti, M., Feddes, R.A., Holtslag, A.A.M., 1998. A remote sensing surface energy balance algorithm for land (SEBAL). 1. Formulation. J. Hydrol. 212-213, 198-212.

Bastiaanssen, W.G.M., Noordman, E.J.M., Pelgrum, H., Davids, G., Thoreson, B.P., Allen, R.G., 2005. SEBAL model with remotely sensed data to improve waterresources management under actual field conditions. J. Irrig. Drain. Eng. 131, 85-93.

Bastiaanssen, W.G.M., Pelgrum, H., Soppe, R.W.O., Allen, R.G., Thoreson, B.P., Teixeira, A.H.d.C., 2008. Thermal infrared technology for local and regional scale irrigation analysis in horticultural systems. ISHS Acta Hortic. 792, 33-46.

Bonachela, S., Orgaz, F., Villalobos, F.J., Fereres, E., 1999. Measurement and simulation of evaporation from soil olive orchards. Irrig. Sci. 18, 205-211.

Cammalleri, C., Anderson, M.C., Ciraolo, G., D’Urso, G., Kustas, W.P., La Loggia, G., Minacapilli, M., 2012. Applications of a remote sensing-based two-source energy balance algorithm for mapping surface fluxes without in situ air temperature observations. Remote Sens. Environ. 124, 502-515.

Cammalleri, C. Rallo, G. Agnese, C., Ciraolo, G. Minacapilli, M., Provenzano, G., 2013. Combined use of eddy covariance and sap flow techniques for partition of ET fluxes and water stress assessment in an irrigated olive orchard. Agric. Water Manage. 120, 89-97.

Cuevas, M.V., Martin-Palomo, M.J., Diaz-Espejo, A., Torres-Ruiz, J.M., RodriguezDominguez, C.M., Perez-Martin, A., Pino-Mejías, R., Férnandez, J.E., 2013. Assessing water stress in a hedgerow olive orchard from sap flow and trunk diameter measurements. Irrig. Sci. 31, 729-746.

Daamen, C.C., Simmonds, J.S., Wallace, J.S., Laryea, K.B., Sivakumar, M.V.K., 1993. Use of microlysimeters to measure evaporation from sandy soils. Agric. Forest Meteorol. 65, 159-173.

Duarte, F., Jones, N., Fleskens, L., 2008. Traditional olive orchards on sloping land: sustainability or abandonment? J. Environ. Manage. 89, 86-98.

Er-Raki, S., Chehbouni, A., Boulet, G., Williams, D.G., 2010. Using the dual approach of FAO-56 for partitioning ET into soil and plant components for olive orchards in a semi-arid region. Agric. Water Manage. 97, 1769-1778.

Fandiño, M., Cancela, J.J., Rey, B.J., Martínez, E.M., Rosa, R.G., Pereira, L.S., 2012. Using the dual- $K_{c}$ approach to model evapotranspiration of albariño vineyards (Vitis vinifera L. cv. albariño) with consideration of active ground cover. Agric. Water Manage. 112, 75-87.

FAOSTAT, 2011. FAO Statistics Division 2013. Food and Agriculture Organization of the United Nations, <http://faostat.fao.org/site/567/default.aspx\#ancor>.

Fernández, J.E., Moreno, F., Girón, I.F., Blázquez, O.M., 1997. Stomatal control of water use in olive tree leaves. Plant Soil 190, 179-192.

Fernández, J.E., Palomo, M.J., Díaz-Espejo, A., Clothier, B.E., Green, S.R., Giróna, I.F., Moreno, F. 2001. Heat-pulse measurements of sap flow in olives for automating irrigation: tests, root flow and diagnostics of water stress. Agric. Water Manage. 51, 99-123.

Ferreira, M.I., Paço, T.A., Silvestre, J., 2004. Combining techniques to study evapotranspiration in woody crops: application to small areas - two case studies. Acta Hortic. 664, 225-232.

Foken, T., Leuning, R., Oncley, S.P., Mauder, M., Aubinet, M., 2011. Corrections and Data Quality. In: Aubinet, M., Vesala, T., Papale, D. (Eds.), Eddy Covariance: a Practical Guide to Measurement and Data Analysis. Springer, Berlin, Heidelberg.

Freixa, E., Gil, J.M., Tous, J., Hermoso, J.F., 2011. Comparative study of the economic viability of high- and super-high-density olive orchards in Spain. Acta Hortic. (ISHS) 924, 247-254.

Granier, A., 1985. Une nouvelle méthode pour la mesure du flux de sève brute dans le tronc des arbres. Annales des Sciences Forestières 42, 193-200.

Hoedjes, J.C.B., Chehbouni, A., Jacob, F., Ezzahar, J., Boulet, G., 2008. Deriving daily evapotranspiration from remotely sensed instantaneous evaporative fraction over olive orchard in semi-arid Morocco. J. Hydrol. 354, 53-64.

Iniesta, F., Testi, L., Orgaz, F., Villalobos, F.J., 2009. The effects of regulated and continuous deficit irrigation on the water use, growth and yield of olive trees. Eur. J. Agron. 30, 258-265.

Kaimal, J.C., Finnigan, J.J., 1994. Atmospheric Boundary Layer Flows: Their Structure and Measurement. Oxford University Press, New York, NY.

Kustas, W.P., Norman, J.M., Schmugge, T.J., Anderson, M.C., 2004. Mapping surface energy fluxes with radiometric temperature. Chapter 7. In: Quattrochi, D., Luvall, J. (Eds.), Thermal Remote Sensing in Land Surface Processes. CRC Press Boca Raton, Florida, USA, pp. 205-253.

Lavee, S., Hanoch, E., Wodner, M., Abramowitch, H., 2007. The effect of predetermined deficit irrigation on the performance of cV. Muhasan olives (Olea europaea L.) in the eastern coastal plain of Israel. Sci. Hortic. 112, 156-163.

Liu, Y., Pereira, L.S., Fernando, R.M., 2006. Fluxes through the bottom boundary of the root zone in silty soils: Parametric approaches to estimate groundwater contribution and percolation. Agric. Water Manage. 84, 27-40.

Martins, D.S., Raziei, T., Paulo, A.A., Pereira, L.S., 2012. Spatial and temporal variability of precipitation and drought in Portugal. Nat. Hazards Earth Syst. Sci. $12,1493-1501$.

Minacapilli, M., Agnese, C., Blanda, F., Cammalleri, C., Ciraolo, G., D’Urso, G., Iovino, M., Pumo, D., Provenzano, G., Rallo, G., 2009. Estimation of actual evapotranspiration of Mediterranean perennial crops by means of remotesensing based surface energy balance models. Hydrol. Earth Syst. Sci. 13, 10611074.

Monin A., Obukhov, A., 1954. Basic laws of turbulent mixing in the ground layer of the atmosphere. Trudy Geofiz. Inst. Akad. Nauk SSSR (A 1959 translation (under auspices of American Meteorological Society) is available from Defense 
Technical Information Center, http://handle.dtic.mil/100.2/AD672723), vol. 151, pp. 163-187.

Moriana, A., Villalobos, F.J., Fereres, E., 2002. Stomatal and photosynthetic responses of olive (Olea europaea) leaves to water deficits. Plant, Cell Environ. 25, 395405.

Moriana, A., Orgaz, F., Pastor, M., Fereres, E., 2003. Yield responses of a mature olive orchard to water deficits. J. Am. Soc. Hortic. Sci. 128, 425-431.

Moriasi, D.N., Arnold, J.G., Van Liew, M.W., Bingner, R.L., Harmel, R.D., Veith, T.L. 2007. Model evaluation guidelines for systematic quantification of accuracy in watershed simulations. Trans ASABE 50, 885-900.

Nash, J.E., Sutcliffe, J.V., 1970. River flow forecasting through conceptual models: Part 1. A discussion of principles. J. Hydrol. 10, 282-290.

Orgaz, F., Testi, L., Villalobos, F.J., Fereres, E., 2006. Water requirements of olive orchards - II: determination of crop coefficients for irrigation scheduling. Irrig. Sci. 24, 77-84.

Paço, T., Ferreira, M., Rosa, R., Paredes, P., Rodrigues, G., Conceição, N., Pacheco, C., Pereira, L., 2012. The dual crop coefficient approach using a density factor to simulate the evapotranspiration of a peach orchard: SIMDualKc model versus eddy covariance measurements. Irrig. Sci. 30, 115-126.

Palese, A.M., Nuzzo, V., Favati, F., Pietrafesa, A., Celano, G., Xiloyannisa, C., 2010. Effects of water deficit on the vegetative response, yield and oil quality of olive trees (Olea europaea L., cv Coratina) grown under intensive cultivation. Sci. Hortic. 125, 222-229.

Perrier, A., 1982. Land surface processes: vegetation. In: Eagleson, P. (Ed.), Land Surface Processes in Atmospheric General Circulation Models. Cambridge Univ. Press, pp. 395-448.

Pôças, I., Cunha, M., Pereira, L.S., Allen, R.G., 2013. Using remote sensing energy balance and evapotranspiration to characterize montane landscape vegetation with focus on grass and pasture lands. Int. J. Appl. Earth Obs. 21, 159-172.

Pôças, I., Paço, T.A., Cunha, M., Andrade, J.A., Silvestre, J., Sousa, A., Santos, F.L., Pereira, L.S., Allen, R.G., 2014. Satellite based evapotranspiration of a superintensive olive orchard: application of METRIC algorithm. Biosyst. Eng. http:// dx.doi.org/10.1016/j.biosystemseng.2014.06.019.

Ramos, A.F., Santos, F.L., 2009. Water use, transpiration, and crop coefficients for olives (cv. Cordovil) grown in orchards in Southern Portugal. Biosyst. Eng. 102, 321-333.

Raziei, T., Bordi, I., Martins, D., Pereira, L.S., 2013. Development of high-resolution gridded datasets of monthly temperature for Portugal. In: Maia, R., Brito, A.G., Teixeira, A.S., Valente, J.T., Pêgo, J.P., (Eds.), Water Resources Management in an Interdisciplinary and Changing Context (Proc. 8th Int Conf. EWRA), Porto, pp. 937-944.

Ritchie, J., 1972. Model for predicting evaporation from a row crop with incomplete cover. Water Resour. Res. 8, 1204-1213.

Rosa, R.D., Paredes, P., Rodrigues, G.C., Alves, I., Fernando, R.M., Pereira, L.S., Allen, R.G., 2012a. Implementing the dual crop coefficient approach in interactive software. 1. Background and computational strategy. Agric. Water Manage. 103, $8-24$.
Rosa, R.D., Paredes, P., Rodrigues, G.C., Fernando, R.M., Alves, I., Pereira, L.S., Allen, R.G., 2012b. Implementing the dual crop coefficient approach in interactive software: 2. Model testing. Agric. Water Manage. 103, 62-77.

Santos, C., Lorite, I.J., Allen, R.G., Tasumi, M., 2012. Aerodynamic parameterization of the satellite-based energy balance (METRIC) model for ET estimation in rainfed olive orchards of Andalusia, Spain. Water Resour. Manage. 26, 3267-3283.

Schuepp, P.H., Leclerc, M.Y., Macpherson, J.I., Desjardins, R.L., 1990. Footprint prediction of scalar fluxes from analytical solutions of the diffusion equation. Bound-Lay. Meteorol. 50, 355-373.

Silva, R.M., Paço, T.A., Ferreira, M.I., Oliveira, M., 2008. Transpiration of a kiwifruit orchard estimated using the Granier sap flow method calibrated under field conditions. Acta Hortic. 792, 593-600.

Siqueira, J.M., Paço, T.A., Silvestre, J., Santos, F.L., Falcão, A.O., Pereira, L.S., 2014 Generating fuzzy rules by learning from olive tree transpiration measurement an algorithm to automatize Granier sap flow data analysis. Comput. Electron. Agric. 101, 1-10.

Tasumi, M., Allen, R.G., 2007. Satellite-based ET mapping to assess variation in ET with timing of crop development. Agric. Water Manage. 88, 54-62.

Testi, L., Villalobos, F.J., Orgaz, F., 2004. Evapotranspiration of a young irrigated olive orchard in southern Spain. Agric. Forest Meteorol. 121, 1-18.

Testi, L., Orgaz, F., Villalobos, F.J., 2006a. Variations in bulk canopy conductance of an irrigated olive (Olea europaea L.) orchard. Environ. Exp. Bot. 55, 15-28.

Testi, L., Villalobos, F.J., Orgaz, F., Fereres, E., 2006b. Water requirements of olive orchards: I. Simulation of daily evapotranspiration for scenario analysis. Irrig. Sci. 24, 69-76.

Tian, F., Qiu, G., Yang, Y., Lu, Y., Xiong, Y., 2013. Estimation of evapotranspiration and its partition based on an extended three-temperature model and MODIS products. J. Hydrol. 498, 210-220.

Timmermans, W.J., Kustas, W.P., Anderson, M.C., French, A.N., 2007. An intercomparison of the Surface Energy Balance Algorithm for Land (SEBAL) and the Two-Source Energy Balance (TSEB) modeling schemes. Remote Sens. Environ. 108, 369-384.

Villalobos, F.J. Orgaz, F. Testi, L.,Fereres, E, 2000, Measurement and modeling of evapotranspiration of olive (Olea europaea L.) orchards. Eur. J. Agron. 13, 155163.

Villalobos, F.J., Testi, L., Orgaz, F., García-Tejera, O., Lopez-Bernal, A., González-Dugo, M.V., Ballester-Lurbe, C., Castel, J.R., 2013. Modelling canopy conductance and transpiration of fruit trees in Mediterranean areas: a simplified approach. Agric. Forest Meteorol. 171-172, 93-103.

Wei, Z., Paredes, P., Liu, Y. Chi, W.-W., Pereira, L.S, 2014. Modelling transpiration, soil evaporation and yield prediction of soybean in North China Plain. Agric. Water Manage. http://dx.doi.org/10.1016/j.agwat.2014.05.004.

Willmott, C.J., 1981. On the validation of models. Phys. Geogr. 2, 184-194.

Zhao, N., Liu, Y., Cai, J., Paredes, P., Rosa, R.D., Pereira, L.S., 2013. Dual crop coefficient modelling applied to the winter wheat - summer maize crop sequence in North China Plain: basal crop coefficients and soil evaporation component. Agric Water Manage. 117, 93-105. 